OPEN ACCESS

Edited by:

Hajime Hirase,

University of Copenhagen, Denmark

Reviewed by:

Enrico Cherubini,

European Brain Research Institute,

Emilio J. Galvan,

Instituto Politécnico Nacional de México (CINVESTAV), Mexico

*Correspondence:

Angel Nuñez

angel.nunez@uam.es

Specialty section:

This article was submitted to

Cellular Neurophysiology,

a section of the journal

Frontiers in Cellular Neuroscience

Received: 04 January 2021 Accepted: 28 January 2021 Published: 04 March 2021

Citation: Nuñez A and Buño W (2021) The Theta Rhythm of the Hippocampus: From Neuronal and Circuit Mechanisms to Behavior. Front. Cell. Neurosci. 15:649262. doi: 10.3389/fncel.2021.649262

\section{The Theta Rhythm of the} Hippocampus: From Neuronal and Circuit Mechanisms to Behavior

\author{
Angel Nuñez ${ }^{1 *}$ and Washington Buño ${ }^{2}$ \\ ${ }^{1}$ Departamento de Anatomía, Histología y Neurociencia, Facultad de Medicina, Universidad Autonoma de Madrid, Madrid, \\ Spain, ${ }^{2}$ Instituto Cajal, Consejo Superior de Investigaciones Cientificas, Madrid, Spain
}

This review focuses on the neuronal and circuit mechanisms involved in the generation of the theta $(\theta)$ rhythm and of its participation in behavior. Data have accumulated indicating that $\theta$ arises from interactions between medial septum-diagonal band of Broca (MS-DbB) and intra-hippocampal circuits. The intrinsic properties of MS-DbB and hippocampal neurons have also been shown to play a key role in $\theta$ generation. A growing number of studies suggest that $\theta$ may represent a timing mechanism to temporally organize movement sequences, memory encoding, or planned trajectories for spatial navigation. To accomplish those functions, $\theta$ and gamma $(\gamma)$ oscillations interact during the awake state and REM sleep, which are considered to be critical for learning and memory processes. Further, we discuss that the loss of this interaction is at the base of various neurophatological conditions.

Keywords: hippocampal neurons, medial septum, diagonal band of Broca, cholinergic input, NMDA, gamma oscillations

\section{INTRODUCTION}

The hippocampus is the main structure involved in the generation of the 4- to $12-\mathrm{Hz}$ theta $(\theta)$ rhythm, which is one of the most regular EEG oscillation that can be recorded from the mammalian brain. Interest in $\theta$ has flourished from the abundant data indicating that the rhythm is linked with integrative processes critical for higher cognitive functions. Thus, neuronal spiking in widespread brain regions is phase locked to hippocampal $\theta$ oscillations, including somatosensory, entorhinal, or prefrontal cortices (Alonso and Garcia-Austt, 1987; Nuñez et al., 1991, 2006; Kocsis and Vertes, 1994; Hanada et al., 1999; Sirota et al., 2008).

A slow oscillatory activity with the properties of $\theta$ was first described in the hippocampus by Jung and Kornmüller (1938). However, the original detailed analysis of hippocampal $\theta$ was provided by Green and Arduini (1954). Green and Arduini (1954) showed that $\theta$ was associated with an irregular desynchronized activity in the cortex, whereas in contrast, synchronized cortical activity was concurrent with irregular activity in the hippocampus. This link between hippocampal and cortical activities suggested a close relation of $\theta$ with attention, information processing, higher brain functions, and cognition, giving rise to a rapidly growing interest in $\theta$. Indeed, more than 2,000 articles that mention hippocampal $\theta$ have been published from 1950 to 2020, with more than 50 articles published in 2020 . 
Although more than 150 reviews on hippocampal $\theta$ have been published, several aspects of the neuronal and circuit mechanisms involved in the generation of the rhythm and particularly its participation in behavior remain unknown or controversial. Nevertheless, new experimental data and modern interpretation of former results provide insight to those unresolved issues. Therefore, this review focuses on those debated basic mechanisms of $\theta$ genesis and of its relationships with behavior. However, it is of key importance to consider that "after 50 years and hundreds of experiments, there is no widely accepted term that would unequivocally describe behavioral correlate(s) of hippocampal $\theta$ oscillation" (Buzsaki, 2020). Moreover, the physiological inputs triggering the selective activation of hippocampal pyramidal neurons in natural conditions are undefined. Therefore, a large amount of future imaginative research will be required to unravel the functional correlation between behavior and hippocampal $\theta$.

\section{MEDIAL SEPTUM-DIAGONAL BAND OF BROCA AND THETA}

A key contribution was the discovery by Petsche et al. (1962) and Stumpf et al. (1962) of the role of the medial septum (MS) in controlling the activity of the hippocampus and in generating $\theta$. It has been shown that glutamatergic, cholinergic, and GABAergic MS and diagonal band of Broca (DbB) neurons project to the hippocampus (Monmaur and Thomson, 1983; Colom et al., 2005; Desikan et al., 2018; Unal et al., 2018). Indeed, evidence has accumulated suggesting that $\theta$ arises from interactions between MS-DbB and intra-hippocampal neuronal and circuital oscillators (Stumpf et al., 1962; McLennan and Miller, 1974; Stewart and Fox, 1989; Hangya et al., 2009; Huh et al., 2010; Müller and Remy, 2018). Strong support to the above interpretation was provided by lessions of the MS-DbB that blocked hippocampal $\theta$ and rhythmic neuronal activity (Green and Arduini, 1954; Buño et al., 1978; Mitchell et al., 1982). However, the rules of innervation of hippocampus by diverse MS-DbB neurons are unknown, and the contribution of hippocampal neuronal populations and circuits in the genesis of $\theta$ are a matter of debate.

Paired recordings of MS and dorsal hippocampal neurons together with recordings of the hippocampal field activity in anesthetized rats suggested that rhythmic hippocampal neuronal activity and field $\theta$ depended upon the rhythmic activity of MS neurons (Macadar et al., 1970; Roig et al., 1970). Importantly, field $\theta$ and rhythmic activity of hippocampal neurons was only present when MS neurons fired rhythmically. However, a group of MS neurons fired rhythmic bursts in the absence of hippocampal $\theta$. Therefore, rhythmicity in the MS can be independent from the hippocampal $\theta$, but the hippocampal $\theta$ rhythm narrowly depends on MS neuron rhythmicity (Figures 1A,B). The rhythmic MS neurons that fire both with or without field $\theta$ could play a leading role in triggering the rhythmic activity of other MS neurons leading to the generation of hippocampal $\theta$. In addition to the MS-DbB neurons that fire rhythmic bursts, there were also non-rhythmic MS-DbB neurons (Buño et al., 1978;
Gaztelu and Buño, 1982; Alonso and Garcia-Austt, 1987; Barrenechea et al., 1995; Pedemonte et al., 1998).

The analysis of septo-hippocampal pairs revealed three main behaviors: (i) when both neurons were rhythmic ( $\theta$-pairs), they fired bursts phase locked with the $\theta$ waves and showed rhythmic cross-correlation histograms; (ii) pairs with a rhythmic and a non-rhythmic neuron (mixed pairs) showed periodic cross-correlation histograms, and both neurons showed firing relationships with the field $\theta$; and (iii) finally, non-rhythmic pairs were uncorrelated and did not show a relationship with field $\theta$. Importantly, similar types of rhythmic and of non-rhythmic neurons with and without a relationship with $\theta$ were found in the hippocampus (see the "Phase Reset of Theta" section below).

Simultaneous intracellular recordings of MS-DbB neurons and of the hippocampal field activity in anesthetized rats revealed neurons that showed large continuous periodic membrane potential $(\mathrm{Vm})$ oscillations and action potential bursts (i.e., intracellular $\theta$; Pedemonte et al., 1998). These neurons displayed essentially identical activity both in the absence or in the presence of field $\theta$, suggesting that they played a key role in hippocampal $\theta$ genesis. Other neurons that showed intracellular $\theta$ could sporadically fire high amplitude slow spikes and action potential bursts. A third group displayed lower amplitude intracellular $\theta$ and briefer bursts. These two last groups only showed rhythmicity during field $\theta$.

Using a similar experimental design, Barrenechea et al. (1995) showed that neurons in the lateral septum could also display intracellular $\theta$ and fire in close relation to the field $\theta$. Taken together, the above results suggest that hippocampal $\theta$ oscillations critically depend on the rhythmic neuronal activity of the MS-DbB. The functional role of the non-rhythmic septo-hippocampal neurons that fire in relation with the $\theta$ rhythm and the network mechanism that underlie this unexpected correlation are intriguing and remain to be determined. Accordingly, these neurons, although nonrhythmic, carry information about $\theta$ oscillations. Tentatively, the non-rhythmic neurons could evoke transient changes of the rhythm such as phase reset (see the "Phase Reset of Theta" section below).

\section{The Cholinergic Medial Septum-Diagonal Band of Broca Input}

Initially, it was proposed that the combined effects of a background excitatory influence provided by cholinergic MS-DbB inputs interacting with a precisely timed rhythmic inhibition provided the main excitatory and inhibitory inputs required to generate $\theta$ (Andersen and Eccles, 1962; Petsche et al., 1968; Smythe et al., 1992; Desikan et al., 2018). Data in support of the cholinergic contribution to hippocampal $\theta$ are: (i) increased release of acetylcholine (ACh) during $\theta$ (Dudar, 1977); (ii) induction of $\theta$ by $\mathrm{ACh}$ and by cholinergic agonist (Alonso and Garcia-Austt, 1987; MacVicar and Tse, 1989; Bland and Colom, 1993); (iii) production of $\theta$ by the increased cholinergic activity caused by blockade of ACh hydrolysis (Macadar et al., 1970; Roig et al., 1970; Buño et al., 1978; Gaztelu and Buño, 1982); and (iv) blockade of $\theta$ by specific cholinergic antagonists 
A Dorsal Hippocampal EEG Ryhthmic SM neurons
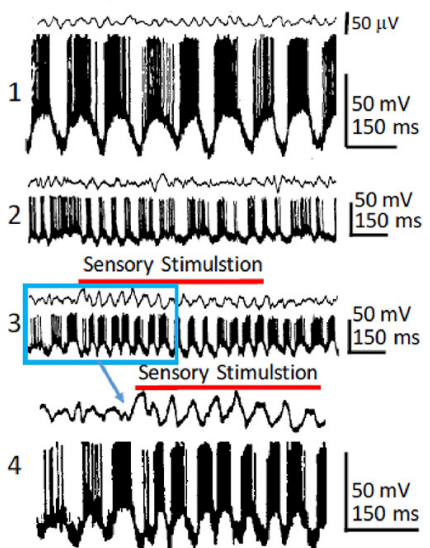
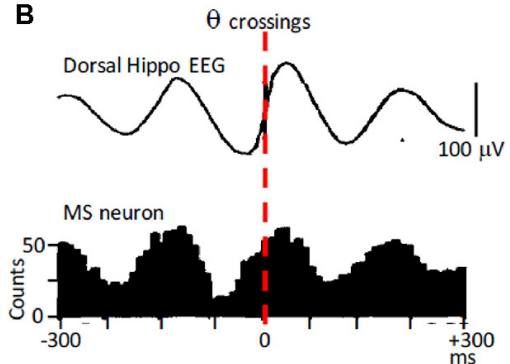

C

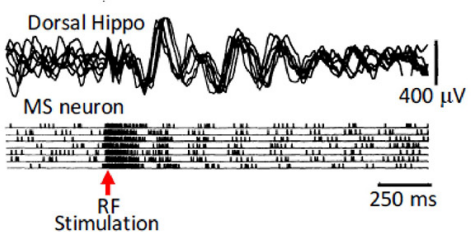

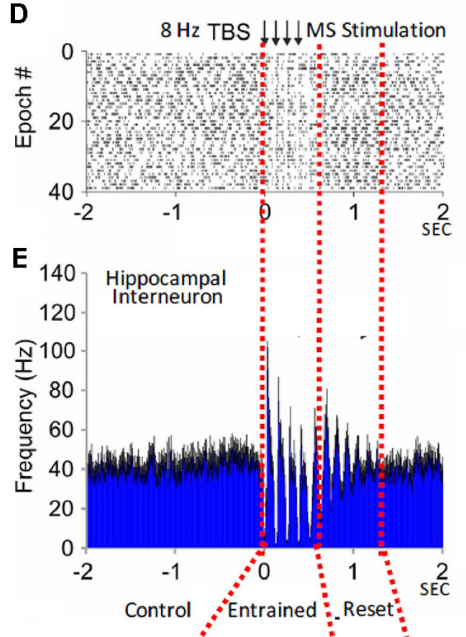

FIGURE 1 | Rhythmic medial septum-diagonal band of Broca (MS-DbB) neurons and theta ( $\theta$ ): in vivo recordings. (A1) Intracellular recordings of a bursting neuron with large spontaneous $\theta$-like membrane potential oscillations (lower) in the absence of $\theta$ in the hippocampal EEG (upper). (A2) As (A1), but irregular bursting and $\theta$. (A3) Change to higher amplitude $\theta$ and higher frequency rhythmic bursting induced by sensory stimulation (gentle stroking the animal's back; red horizontal bar). (A4) Expanded version of part of (A3); (blue square). (B upper) Cross-correlation function (triggered by $\theta$ zero crossings, interrupted red line) of hippocampal EEG. (B lower) Cross-correlation histogram of rhythmic busting medial septum (MS) neuron activity showing strong phase locking between both activities. Note the phase advance of the neuron with $\theta$. (C) Reset of hippocampal $\theta$ (upper) and of rhythmic bursting MS neuron (lower) triggered by reticular formation stimulation (red arrow); notice the increased amplitude of reset $\theta$. (D) Raster plot showing successive epochs of rhythmic bursting hippocampal interneuron before, during, and after theta burst electrical stimulation of the MS. (E) Cross-correlation histogram showing entrainment by stimulation followed by phase reset (interrupted red lines). Modified from: (A) Barrenechea et al. (1995); (B,C) Gaztelu and Buño (1982); (D,E) Mamad et al. (2015).

(Monmaur and Thomson, 1983; Vinogradova, 1995; Li et al., 2007; McQuiston, 2010).

Interestingly, $\mathrm{ACh}$ is released by cholinergic MS-DbB terminals in the interstitial space where it is hydrolyzed by acetylcholinesterase, suggesting a gradual protracted activation by "ambient" ACh (McCormick and Prince, 1986; Descarries et al., 2004; Ovsepian et al., 2004; Yamasaki et al., 2010; Domínguez et al., 2014). The induction of $\theta$ by ACh is mediated predominantly by muscarinic receptors (mAChRs) expressed in hippocampal pyramidal neurons (Monmaur and Thomson, 1983; Ovsepian et al., 2004; Fernández de Sevilla et al., 2020). In addition, the activity of GABAergic interneurons is controlled both through $\mathrm{mAChR}$ and nicotinic receptors (nAChRs) by a cholinergic input from the basal forebrain, suggesting that nAChRs also contribute in the genesis of $\theta$ (Frotscher and Léránth, 1985; Gray et al., 1996; Griguoli et al., 2010; Drever et al., 2011; Griguoli and Cherubini, 2012; Yakel, 2012; Cheng and Yakel, 2015).

The cholinergic effects on septo-hippocampal activity are behavior dependent, since selective optogenetic activation of cholinergic MS-DbB neurons triggered strong network effects during inactive behavioral states and weak effects during active behaviors in rats (Mamad et al., 2015). In addition, non-selective MS-DbB theta-burst electrical stimulation increased field $\theta$ synchronization and power, reset hippocampal rhythmic bursting neurons, entrained hippocampal place cells, and tuned the spatial properties (Figures 1D,E). Furthermore, optogenetic activation of cholinergic MS-DbB neurons at $\theta$ frequencies increased the power but caused poor entrainment of the hippocampal $\theta$, an effect that was behavior dependent since it was stronger under anesthesia compared to awake mice (Vandecasteele et al., 2014). Taken together the above findings support the idea that when cholinergic neurons are highly activated during active exploration, additional activation has a reduced effect on hippocampal oscillations.

\section{The GABAergic Medial Septum-Diagonal Band of Broca Input}

The contribution of rhythmic GABAergic MS-DbB neurons in the generation of $\theta$ has been firmly established (Andersen and Eccles, 1962; Smythe et al., 1992; Joshi et al., 2017; Unal et al., 2018). Rhythmic MS-DbB interneurons express parvalbumin and the hyperpolarization-activated cyclic nucleotide-gated $(\mathrm{HCN})$ channels, which can contribute to their oscillatory properties (Varga et al., 2008; Hangya et al., 2009). Importantly, rhythmic GABAergic MS-DbB neurons mainly contact hippocampal inhibitory interneurons of all types that exert a strong rhythmic inhibition upon pyramidal neurons (Freund, 1992; Smythe et al., 1992; Hangya et al., 2009; Unal et al., 2018), thereby contributing to $\theta$ via rhythmic disinhibition (Tóth et al., 1997). Although debated, the firing synchronization provided by electrical synapses through gap junctions between inhibitory interneurons could also contribute to the generation of the $\theta$ rhythm (Konopacki et al., 2014; Posuszny, 2014; Schoenfeld et al., 2014).

Recent evidence obtained with optogenetic entrainment at $\theta$ frequencies of specific GABAergic MS neurons in behaving mice revealed a vital involvement of these neurons in the 
generation and entrainment of the hippocampal field $\theta$ and of rhythmic action potential bursting of hippocampal neurons, whereas optogenetic silencing of these neurons strongly reduced field $\theta$ (Bender et al., 2015; Boyce et al., 2016; Gangadharan et al., 2016). The entrainment was not modified behavior, suggesting that although the synchronization of GABAergic MS neurons plays a vital role in the generation of $\theta$, the rhythmically entrained circuits do not participate in behavior. Although the hippocampal field could follow the optogenetic activation of GABAergic MS neurons at $\theta$ frequencies, hippocampal neurons could also discharge at higher frequencies (Zutshi et al., 2018). The different behaviors of the field and neuronal activities suggest that GABAergic MS neurons trigger circuit mechanisms that accelerate the rhythmicity of hippocampal neurons. Indeed, MS GABAergic neurons regulate circuit activity via rhythmic disinhibition of pyramidal neurons (Freund, 1992; Smythe et al., 1992; Tóth et al., 1997; Buzsaki, 2002; Unal et al., 2012, 2018). These studies provide strong support to the notion that septal GABAergic projections regulate the hippocampal field potential oscillations via $\theta$ hippocampal interneurons.

\section{The Glutamatergic Medial}

\section{Septum-Diagonal Band of Broca Input}

Although excitatory MS-DbB inputs had previously been shown to participate in the production of $\theta$ (Núñez et al., 1987, 1990b; Leung and Shen, 2004; Colom et al., 2005; Huh et al., 2010; Khakpai et al., 2016), recent experimental evidence has provided strong support to the contribution of glutamatergic MS-DbB neurons in the genesis of hippocampal $\theta$. Accordingly, optogenetic activation of specific glutamatergic excitatory MS-DbB neurons both in vitro and in behaving animals showed that those neurons provided a critical contribution to the genesis of hippocampal $\theta$, mainly through local modulation of septal neurons (Robinson et al., 2016). Huh et al. (2010), using both in vitro slice and septo-hippocampal preparations, reported that activation of identified glutamatergic MS-DbB neurons led to fast AMPA-mediated synaptic responses in hippocampal pyramidal neurons. In addition, activation of MS-DbB neurons with NMDA microinjections induced rhythmic bursting at $\theta$ frequencies both in hippocampal and MS-DbB neurons (see "Intrinsic Pyramidal Neuron Properties and Theta" and "Intrahippocampal Circuits and Theta" sections below).

\section{INTRINSIC PYRAMIDAL NEURON PROPERTIES AND THETA}

\section{In vivo Studies}

Although the activity of the septo-hippocampal pathway and intrahippocampal circuits provide an important contribution to $\theta$ genesis, data has accumulated suggesting that intrinsic properties of hippocampal neurons also participate. Indeed, slow spikes were recorded in CA3-CA1 neurons of anesthetized rats together with the usual $\mathrm{Na}^{+}$type action potential bursts during field $\theta$. Slow spikes fired an overriding high-frequency burst of fast $\mathrm{Na}^{+}$-mediated action potentials (Núñez et al., 1987, 1990a; Figures 2B,C). Depolarizing pulses triggered rhythmic slow spikes at rates that increased with depolarization. In the absence of field $\theta$, strong dendritic depolarization by current injection induced large amplitude oscillation in the $\theta$ frequency range and resulted in a voltage-dependent phase precession of the action potentials as occurs in behaving animals (Kamondi et al., 1998).

In similar in vivo conditions, inhibition of $\mathrm{Na}^{+}$conductance by QX-314-loading prevented fast $\mathrm{Na}^{+}$-mediated action potentials, but slow QX-314-resistant putative $\mathrm{Ca}^{2+}$ spikes remained (Nuñez and Buño, 1992; Figure 2D). In terms of their possible participation in the generation of $\theta$, the slow QX-314-resistant events display the correct frequency and duration and can oscillate intrinsically. Accordingly, rhythmic bursts at $\theta$ frequency, similar to those triggered with intracellular recorded slow spikes, have been recorded in vivo in hippocampal neurons during periods of $\theta$ rhythm induced by sensory stimulation in anesthetized rats (Núñez et al., 1987) or when head-restrained mice, running on a spherical treadmill, entered in the recorded cell's place field (Harvey et al., 2009). Accordingly, slow spikes provide pyramidal neurons with intrinsic conductance, which can boost $\theta$ oscillations generated by network properties.

\section{In vitro Studies}

Recordings of CA1 pyramidal neurons in rat hippocampal slices revealed that plateau potentials and rhythmic $\theta$-like intrinsic Vm oscillations were evoked by depolarizing current pulses in an important proportion of the neurons (García-Muñoz et al., 1993). Rhythmic high threshold slow TTX-resistant spikes were triggered and entrained by imposed sinusoidal transmembrane currents at $\theta$ frequencies. The above findings suggest that NMDA- and $\mathrm{Ca}^{2+}$-mediated spikes provide an important depolarizing drive, that boosts the otherwise small depolarization supplied by EPSPs, to generate the high-frequency rhythmic bursts of fast $\mathrm{Na}^{+}$-mediated action potentials that typifies pyramidal neuron activity during field $\theta$.

In addition to the slow NMDA- and $\mathrm{Ca}^{2+}$-mediated spikes, voltage-gated $\mathrm{Na}^{+}$-mediated conductance underlie subthreshold rhythmic membrane oscillation in entorhinal cortex neurons, which could play an important part in the genesis of the $\theta$ rhythm (Alonso and Llinas, 1989; Dickson et al., 2000). These subthreshold $\mathrm{Na}^{+}$-dependent oscillations can also be recorded from CA1 hippocampal pyramidal neurons, suggesting a more direct contribution to hippocampal $\theta$ oscillations (García-Muñoz et al., 1993).

\section{INTRAHIPPOCAMPAL CIRCUITS AND THETA}

\section{Analysis In vivo}

Due to the small amplitude of unitary EPSPs that on the average do not reach the firing threshold of hippocampal pyramidal neurons (Sayer et al., 1989; Fernández de Sevilla et al., 2002), action potential firing in CA1 pyramidal neurons is scarce during desynchronized hippocampal field activity (Schwartzkroin, 1975; Buzsaki and Eidelberg, 1983; Núñez et al., 1987; Csicsvari et al., 1999). However, during $\theta$, there is strong increase in synchronized rhythmic activity of MS-DbB neurons that results in temporal and spatial 


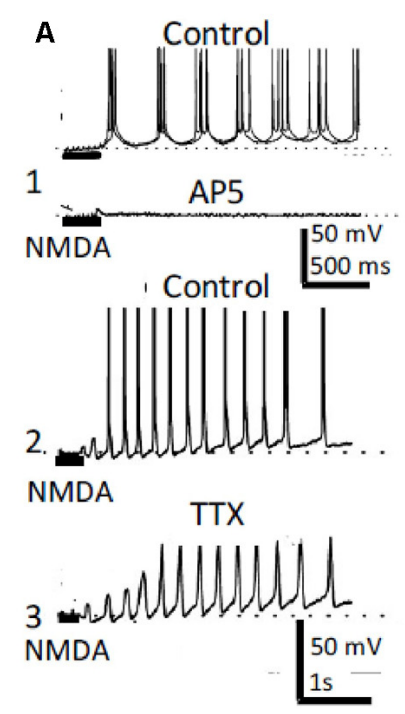

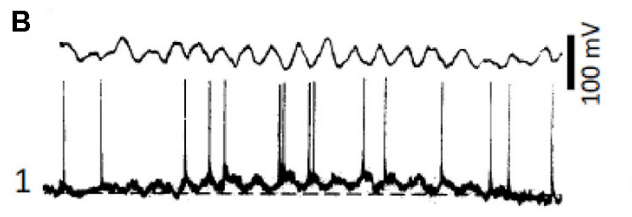
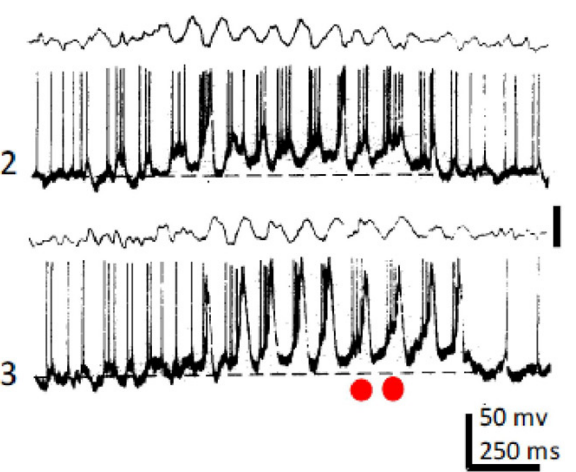
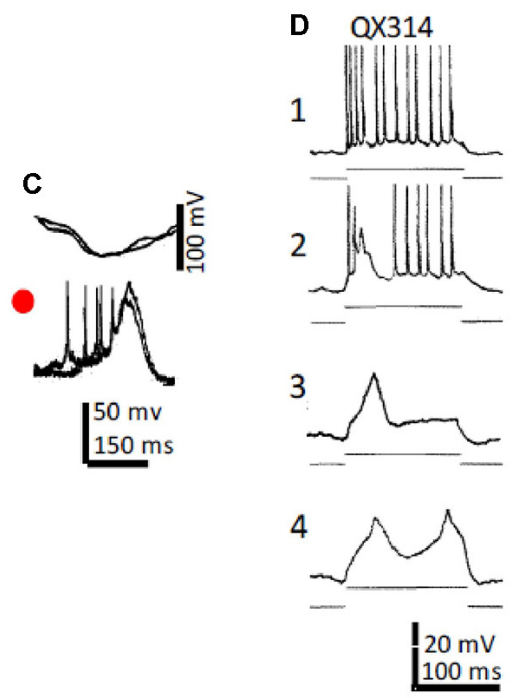

FIGURE 2 | Rhythmic CA1 pyramidal neurons and theta $(\theta)$ : in vitro and in vivo recordings. (A1) Representative in vitro patch recordings showing $\theta-$ like membrane potential oscillations and action potential bursts induced by NMDA microiontophoresis at the apical dendrites of a CA1 pyramidal neuron (upper); superfision of AP5 blocked the NMDA response (lower). (A2) As (A1), but another neuron showing the effects of NMDA microiontophoresis in control ringer. (A3) Superfusion of TTX abolished action potential bursting but oscillations, NMDA- and $\mathrm{Ca}^{2+}$-spikes remained. (B1) Representative in vivo recordings of spontaneous CA1 EEG (upper) and CA1 neuron showing typical $\theta$ oscillations and single and occasional action potential bursts (lower). (B2,3) Same as (B1) in a CA3 neuron showing slow spikes riding on a sustained depolarization and firing rhythmic action potential bursts time-locked with $\theta$ oscillations; the red dots in (A3) correspond to the superimposed expanded records in panel (C). (D1) Representative in vivo tonic discharge evoked by a depolarizing current pulse applied immediately after impalement with a QX314-filled electrode. (D2) Record obtained later after impalement showing a slow putative $\mathrm{Ca}^{2+}$ spike and fewer and smaller action potentials. (D3,4) Even later, action potentials were blocked and one and two slow spikes were triggered with increasing pulse intensities (1-4 same neuron). (A) Modified from Bonansco and Buño (2003); (B,C) modified from Núñez et al. (1987); (D) modified from Nuñez and Buño (1992).

summation of excitatory postsynaptic potentials (EPSPs) that exceed the firing threshold of hippocampal pyramidal neurons. The excitatory input of MS-DbB neurons onto hippocampal pyramidal neurons is paced by the rhythmic GABAergic inhibitory postsynaptic potentials (IPSPs) from both inhibitory MS-DbB and intrahippocampal interneurons. Interestingly, different interneuron types innervate distinctive domains of pyramidal neurons and exhibit specific firing patterns during $\theta$, contributing differentially to hippocampal $\theta$ and ripple oscillations (Klausberger et al., 2003). The diversity of hippocampal interneurons could coordinate the activity of pyramidal cells in different behavioral states. Accordingly, the rhythmic interactions between EPSPs and IPSPs generate the intracellular $\theta$ and action potential bursting that typifies pyramidal neurons during $\theta$ (Andersen and Eccles, 1962; Núñez et al., 1987, 1990a; MacVicar and Tse, 1989; Fujita, 1991; Cobb et al., 1995; Csicsvari et al., 1999).

Infusion of NMDA in the entorhinal cortex (Leung and Shen, 2004; Gu et al., 2017) and microiontophoresis of NMDA close to the apical dendrites of hippocampal pyramidal neurons in anesthetized rats induced the generation of hippocampal $\theta$, demonstrating the involvement of glutamatergic NMDA receptors in intrahippocampal circuit activity (Puma et al., 1996; Bland et al., 2007). In addition, the hippocampal $\theta$ rhythm was markedly reduced by infusion of the specific NMDAR blocker AP5 into the lateral ventricles of behaving rats (Leung and Desborough, 1988). Therefore, the glutamatergic MS-DbB neurons can contribute to field $\theta$ acting through NMDARs in hippocampal neurons.

\section{The Theta Rhythm In vitro}

Hippocampal oscillations frequencies within and exceeding the $\theta$ range can be induced in vitro by changes of the ionic environment, activation of ionotropic, and of metabotropic receptors. Superfusion of ACh muscarinic agonists in vitro can induce the intracellular $\theta$ and action potential bursting that typifies CA1 pyramidal neuron activity during $\theta$ oscillations in the natural condition (Konopacki et al., 1987; Bland et al., 1988; Fernández de Sevilla et al., 2006). The muscarinic rhythm is paced by local inhibitory interneurons, which are connected through dendritic electrical synapses and tend to fire synchronously (Traub et al., 2004; Konopacki et al., 2014; Posuszny, 2014; Schoenfeld et al., 2014). Electrical coupling between pyramidal neuron axons have also been reported to contribute (Traub et al., 2004). Superfusion of NMDA in hippocampal slices induces $\theta$-like oscillations, suggesting an important contribution of circuital excitatory synaptic interaction through NMDARs in the genesis of $\theta$ (Kazmierska and Konopacki, 2013).

Tetanic stimulation of Schaffer collaterals (SCs) and microiontophoresis of glutamate at CA1 pyramidal neuron apical dendrites evoked rhythmic Vm oscillations and action potential bursts at $\theta$ frequencies in vitro (Bonansco et al., 2002). Oscillations were clear cut in pyramidal neurons 
placed close to the midline of the dorsal CA1, but not in lateral neurons that fired single-action potentials. Medial neurons exhibited a higher NMDAR density at the apical dendritic shafts than lateral neurons and a larger NMDA current component under voltage-clamp, suggesting that these differences underlie the dissimilar responses of both neuron groups.

NMDA microiontophoresis at the apical dendrites of CA1 pyramidal neurons induced $\theta$-like $\mathrm{Vm}$ oscillations and rhythmic action potential bursts in vitro (Bonansco and Buño, 2003). However, in the absence of NMDAR activation, imposed membrane depolarization and microiontophoresis of AMPA depolarized, but never induced, rhythmic oscillations and bursts. Rhythmic Vm oscillations and bursts induced by NMDA remained under blockade of GABA-mediated inhibition with picrotoxin and of AMPA receptors with CNQX. In contrast, oscillations and bursts were prevented by inhibition of NMDARs with AP5 and in $\mathrm{Mg}^{2+}$-free solutions. Importantly, NMDARmediated Vm oscillations persisted, but action potentials were prevented under blockade of $\mathrm{Na}^{+}$-mediated action potentials with tetrodotoxin (Figure 2A).

Taken together, the above results suggest that $\mathrm{Vm}$ oscillations in hippocampal CA1 pyramidal neurons induced by microiontophoresis of NMDA, glutamate, and by tetanic stimulation of SCs do not depend on circuital interactions. The results suggest that NMDA-induced oscillations relied on the negative slope conductance of the NMDA channel caused by the voltage-dependent $\mathrm{Mg}^{2+}$ block that underlies NMDA spikes (Schiller and Schiller, 2001; Antic et al., 2010) and on high-threshold $\mathrm{Ca}^{2+}$ spikes mediated by activation of L-type voltage-dependent $\mathrm{Ca}^{2+}$ channels (VDCC; Bonansco and Buño, 2003). The large $\mathrm{Ca}^{2+}$-mediated depolarization triggers the high-frequency action potential burst that backpropagates into the apical dendrites of pyramidal neurons inducing a supralinear $\mathrm{Ca}^{2+}$ influx into spines that can induce long-term synaptic plasticity (Lisman, 2017; Sakmann, 2017; Fernández de Sevilla et al., 2020).

\section{PHASE RESET AND ENTRAINMENT OF THETA}

To be considered an oscillator, a neuron or network must be intrinsically rhythmic, and the rhythm must be acceptably regular. Neural oscillators display two distinctive behaviors when perturbed by brief inputs, namely, phase reset and entrainment (e.g., Winfree, 1977; Barrio and Buño, 1990; McClellan and Jang, 1993). Phase reset and entrainment result from the continuously varying excitability of the neural oscillator during the oscillation cycle. In spiking and bursting neural oscillators, the phase is the normalized time since the last action potential. In field recordings of neural oscillations, the phase is the normalized time between successive peaks or successive troughs of the oscillation.

\section{Phase Reset of Theta}

Phase reset is evoked by stimulating an input (i.e., a perturbation) and computing the phase shift or reset of the perturbed rhythm. The perturbation phase-locks the oscillation and results in periodic averages and cross-correlations of the rhythmic field and action potential activity (Figure 1C). Phase reset of $\theta$ and rhythmical hippocampal units can be induced by electrical stimulation of hippocampal afferents both in anesthetized and in behaving rats, and during rapid eye movement (REM) in sleep (García-Sánchez et al., 1978; Gaztelu and Buño, 1982; Lerma and García-Austt, 1985; Alonso et al., 1987; Núñez et al., 1990b; Vinogradova, 1995; Givens, 1996; McCartney et al., 2004; Jackson et al., 2008). Importantly, reset was consistently evoked by stimulation of structures with rich contacts with the MS-DbB, but abolished by destruction of the MS and fornix, suggesting that it could be induced by reset of MS-DbB neurons triggered by input from connected structures (Buño et al., 1978; Brazhnik et al., 1985). An alternative possibility is that direct inhibition of MS neurons by synchronized hippocampal output originally elicited by septal inputs may be the reset mechanism. Indeed, the genesis and tuning of the 0 rhythm is a complex process in which feedback control of the septal pacemaker by hippocampal rhythmic neurons is an important process (Alonso et al., 1987; Müller and Remy, 2018).

Stimulation of areas connected to the MS-DbB could elicit reset with higher frequencies than the spontaneous $\theta$ (Buño et al., 1978; García-Sánchez et al., 1978; Gaztelu and Buño, 1982; Alonso et al., 1987; Núñez et al., 1990b), suggesting independent $\theta$ generator systems, which can produce different rhythms (Kramis et al., 1975). Electrical stimulation of structures projecting to MS-DbB tended to induce phase reset of the field $\theta$ and of the rhythmic bursting neuronal activity. Remarkably, in close agreement with the expected behavior of coupled oscillators, afferent stimulation also resets the MS-DbB rhythmic neuronal activity, resulting in phase reset of both septal and hippocampal oscillations (Gaztelu and Buño, 1982; Alonso et al., 1987; Barrenechea et al., 1995; Pedemonte et al., 1998; Figure 1C). Accordingly, phase reset of $\theta$ has been found during conditioning, operant behavior, and special navigation (see the "Memory and Theta" section below).

\section{Entrainment of Theta}

Entrainment also results from the phase sensitivity of neural oscillators and follows the rules of phase reset typified by phase locking (Winfree, 1977; Barrio and Buño, 1990; McClellan and Jang, 1993; Lakatos et al., 2019). Periodic electrical stimulation of the MS-DbB and lateral septum between 4 and $12 \mathrm{~Hz}$ evoked $1: 1$ entrainment and reset of field $\theta$ and phase locking of action potential bursts in hippocampal interneurons in behaving rats (Mamad et al., 2015; Figures 1D,E). Stimulation beyond the $\theta$ range evoked bursts at higher or lower frequency than stimulation frequencies, suggesting that the septo-hippocampal circuitry is tuned to oscillate in the $\theta$ range (Brazhnik et al., 1985; García-Muñoz et al., 1993).

Interestingly, in agreement with the important influence of inhibition in $\theta$ genesis, reset and entrainment can be induced by activation of individual GABAergic interneurons in hippocampal slices, a mechanism that can synchronize the firing of pyramidal cells (Cobb et al., 1995). Phase reset and entrainment links external stimuli with neuronal rhythmic events (Lakatos et al., 2019). This link has been analyzed in a simple 


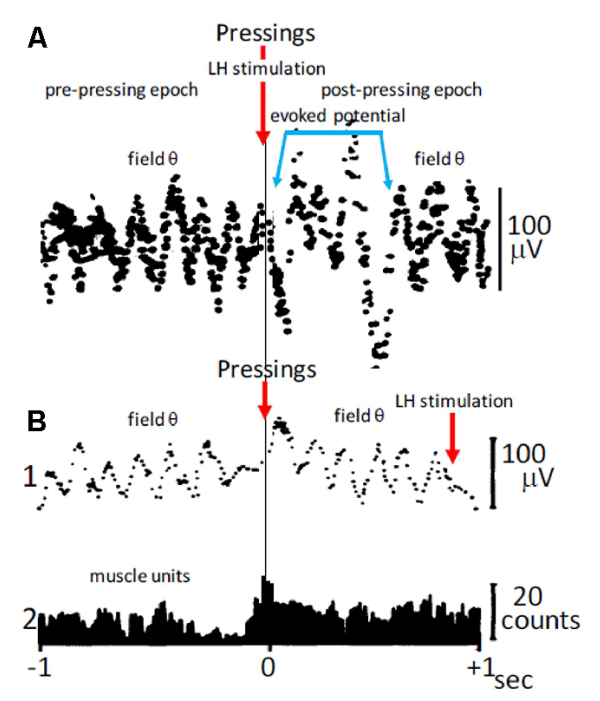

C
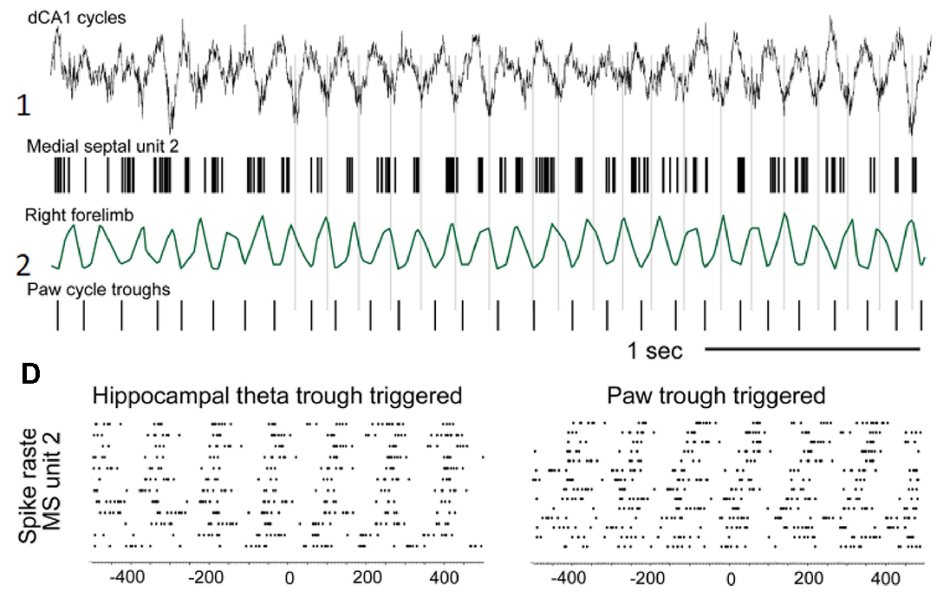

FIGURE 3 | Voluntary movement and $\theta$. (A) Phase relationship of $\theta$ with bar pressings for lateral hypothalamic (LH) electrical self-stimulation. The two superimposed averages triggered by bar pressing onsets (upper arrow) show $\theta$ waves in the pre-pressing epoch and a potential evoked by the LH self-stimulation (blue lines) followed by $\theta$ waves in the post-pressing epoch. (B1) As in (A), average triggered by bar pressing onsets (lower left arrow) but the LH self-stimulation was delayed $(0.9 \mathrm{~s})$ from pressings onsets (lower right arrow). Note the absence of evoked potential and pre- and post-pressing $\theta$ waves in (B1). (B2) Histogram of muscle unit firing from the left forelimb triggered by pressing onsets. (A,B) Two different rats; averages were constructed with 50 successive lever pressings. (C) Phase relationship between MS neuron discharges, step-cycles, and field $\theta$ in mice. (C1) Field $\theta$ and MS neuron action potentials (upper and lower, respectively). (C2) Forelimb movements and paw steps (upper and lower, respectively). (D) Raster plot of MS neuron firings synchronized with $\theta$ cycles and with paw steps (left and right, respectively). (A) Modified from Buño and Velluti (1977); (B) modified from Joshi and Somogyi (2020).

neural pacemaker where it enables the detection of specific input characteristics that depend on the properties and frequency of the oscillator (Buño et al., 1984).

\section{HIPPOCAMPAL THETA RHYTHM AND BEHAVIOR}

Among the many functions that have been attributed to hippocampal $\theta$, we will center on the relationships with locomotion, memory, and spatial navigation (Cherubini and Miles, 2015). A growing number of studies suggest that $\theta$ may represent a timing mechanism where hippocampal pyramidal neurons fire with a higher probability at the phase of the $\theta$ cycle when excitation by MS-DbB glutamatergic neurons added with the sustained excitation supplied by cholinergic inputs is maximal, and periodic perisomatic inhibition is minimal (Núñez et al., 1990b; Freund and Buzsaki, 1996; Csicsvari et al., 1999; Klausberger and Somogyi, 2008; Müller and Remy, 2018; see the "Analysis In vivo" section above). This timing system may represent a general mechanism devised to organize into temporal series, fragmented by $\theta$ oscillations in a moment-by-moment basis of movement sequences, memory encoding, and planned trajectories for spatial navigation.

\section{Locomotion and Theta}

The correlation between locomotion and the amplitude and frequency of the hippocampal $\theta$ have suggested that movement sequences could be regulated by the $\theta$ oscillations (Whishaw and Vanderwolf, 1973; Buño and Velluti, 1977; Vanderwolf et al., 1977; Fuhrmann et al., 2015; Lu et al., 2020). Running speed in behaving animals shows a close correlation with the amplitude and frequency of the $\theta$ oscillations (Rivas et al., 1996; Ahmed and Mehta, 2012; Bender et al., 2015; Lu et al., 2020). Likewise, movements tend to occur at a specified phase of the $\theta$ oscillation (Buño and Velluti, 1977; Semba and Komisaruk, 1978; Joshi and Somogyi, 2020).

In freely behaving rats, bar pressing for electrical self-stimulation of the lateral hypothalamus, averages of hippocampal field activity triggered by the onset of bar pressings, revealed periodic waves with frequencies within the $\theta$ band (5-8 Hz; Figures 3A,B; Buño and Velluti, 1977). The periodic waves in the pre-pressing epoch are only observed if bar pressings tend to occur during a particular phase of the $\theta$ wave, implying that $\theta$ is phase-locked before pressing onsets. Accordingly, the periodic averages suggest that bar pressing onsets occurred at a defined phase of the ongoing field $\theta$ waves. There were also phase-locked $\theta$ waves following pressings superimposed on a potential evoked by the hypothalamic electrical self-stimulation (Figure 3A). Introduction of a delay ( $0.9 \mathrm{~s}$ ) between bar pressings and the electrical self-stimulation delayed the evoked potential, and averages showed phase-locked $\theta$ oscillations before and after bar pressings (Figure 3B1).

Electrolytic lesions of the septum or superior fornix abolished $\theta$ and significantly increased the frequency of bar pressing. Accordingly, the septo-hippocampal mechanisms, which generate $\theta$ are not necessary to maintain self-stimulation (Ward, 1960). However, the increased lever pressing rates following lesions suggest a possible participation in motor timing mechanisms through an inhibitory influence of the septum (Gage et al., 1978). 
The above results taken together suggest that phase-locked $\theta$ may be a corollary of motor mechanisms and perhaps of the timing of motor sequences controlled by $\theta$ cycles. Phaselocked $\theta$ oscillations could contain predictive information about the planning of motor activity (i.e., the future) and of its execution on a moment-by-moment basis that ends when the goal is reached (Whishaw and Vanderwolf, 1973; Wyble et al., 2000; Fuhrmann et al., 2015; Wikenheiser and Redish, 2015). Interestingly, step-cycles during walking in mice show a temporal correlation with $\theta$ oscillations and with the firing of MS neurons, suggesting that rhythmic firing MS cells could coordinate $\theta$ and stepping-related locomotor activity (Joshi and Somogyi, 2020; Figures 3C,D).

These findings fit in with the argument that phase locking of $\theta$ oscillations could regulate the planning and execution of motor activity on a moment-by-moment basis, where information is fragmented and organized into temporal sequences by $\theta$ oscillations. Hippocampal $\theta$ phase locking may thus represent a general neurophysiological mechanism supporting memory formation. It has been proposed that hippocampal neurons operate with future, present, and past events in the $\theta$ cycle sequences that hold spatio-temporal representations (Cei et al., 2014). The phase relationship of bar pressings with $\theta$ and of the subsequent hypothalamic stimulation may result in synaptic plasticity that is favored during a specific phase of the $\theta$ cycle (Buño and Velluti, 1977; Huerta and Lisman, 1995; McCartney et al., 2004).

\section{Memory and Theta}

Although it has been firmly established that hippocampal $\theta$ carries spatial information (see the "Spatial Navigation and Theta" section below), a growing number of studies indicate that non-spatial information can be also conveyed by the hippocampal $\theta$ rhythm, suggesting that $\theta$ operates as a general mechanism for encoding continuous, task-relevant information (Radulovacki and Adey, 1965; Adey, 1967; Wood et al., 1999; Moita et al., 2003; MacDonald et al., 2011; Aronov et al., 2017). In addition, several studies have provided conclusive data suggesting that hippocampal lesions interfere with learning and memory (Barbizet, 1963; Adey, 1967; Zola and Squire, 2001; Burgess et al., 2002).

In an interesting study using a T-maze discriminative response paradigm, Radulovacki and Adey (1965) showed that during discrimination, averages triggered by a brief tone exhibited periodic $\theta$ waves (phase reset), whereas the amplitude and regularity of the waves were reduced or altogether absent when the animal was orienting. The results of Radulovacki and Adey (1965) suggest that the $\theta$ phase reset may relate to processes that underlie acquisition and storage of behaviorally relevant information and speculate that "they might underlie the most fascinating continuum in consciousness leading from the immediate past through the present to the immediate future."

During early training in a classical conditioning paradigm that enabled separation of conditioned responses and purposedirected responses, the responses evoked by the conditioned stimulus were of low amplitude and usually followed by phase reset of the hippocampal $\theta$ (Buzsaki et al., 1979).
However, with more training, $\theta$ reset decreased and short-latency high-voltage evoked potentials were evoked by the conditioned stimulus. In this condition, orienting activity decreased to the preconditioning level, suggesting changes in oscillation characteristics related to orienting, attentional factors rather than to movements. Although the results suggest that non-spatial information is encoded by a temporal code organized by $\theta$ oscillations, how non-spatial information is integrated into memory at the $\theta$ timescale is a critical issue that remains to be determined. The experimental analysis of the temporal organization of memory and $\theta$ has been limited by experiments that lack the temporal resolution to segregate encoding and retrieval. In human subjects asked to recall previously learned word-object associations, the neural signatures of memory retrieval fluctuate and are time locked to the phase of an ongoing theta oscillation (Kerren et al., 2018). It has been recently reported that in human patients performing a spatial memory task phase locking at the peak of $\theta$ preceded eye fixations to retrieved locations, whereas phase locking at the trough of $\theta$ followed fixations to novel object-locations, indicating that the hippocampus coordinates memory-guided eye movements (Kragel et al., 2020). These human results strongly suggest that memory encoding retrival is gated by $\theta$-linked neuronal activity.

\section{Spatial Navigation and Theta}

The original detailed analysis of the relationship between spatial navigation and hippocampal $\theta$ was provided by O'Keefe and Recce (1993). O'Keefe and Recce (1993) discovered that hippocampal neurons began firing at a particular phase of the $\theta$ cycle as the rat entered the field and fired at progressively earlier phases of the $\theta$ cycle as the rat passed through the neuron's place field (Figure 4). This phenomenon was called phase precession because the firing phase of the "place cell" was highly correlated with the rat's spatial location, whereas temporal aspects of behavior were not. Several studies have shown that place cells can represent a position ahead of the animal in the field, suggesting that phase precession can predict the sequence of upcoming positions (Lisman and Redish, 2009; Buzsaki and Moser, 2013). Therefore, the activity in the hippocampus can be encoded as the sequence of action potentials within each $\theta$ cycle to signal information about future, present, and past locations and events (Dusek and Eichenbaum, 1998; Lisman and Redish, 2009; Pfeiffer and Foster, 2013; Sugar and Moser, 2019). Accordingly, hippocampal neurons discharge in function of the animal's location and direction of movement in a given environment suggesting that place cells play a role in navigational planning (O'Keefe and Dostrovsky, 1971; O’Keefe and Recce, 1993; Wilson and McNaughton, 1993; Brown et al., 1998; Zhang et al., 1998; Jensen and Lisman, 2000).

The above-described results imply that knowledge of the speed and direction of movement and landmark information are required to continuously compute the position of the animal during spatial navigation. Information on speed of locomotion is critical to maintain the correct phase relationships between place cell activity and past, present, and future positions. When the animal navigates the place field of a neuron, the number of $\theta$ cycles decreases with running speed, but the number 
A

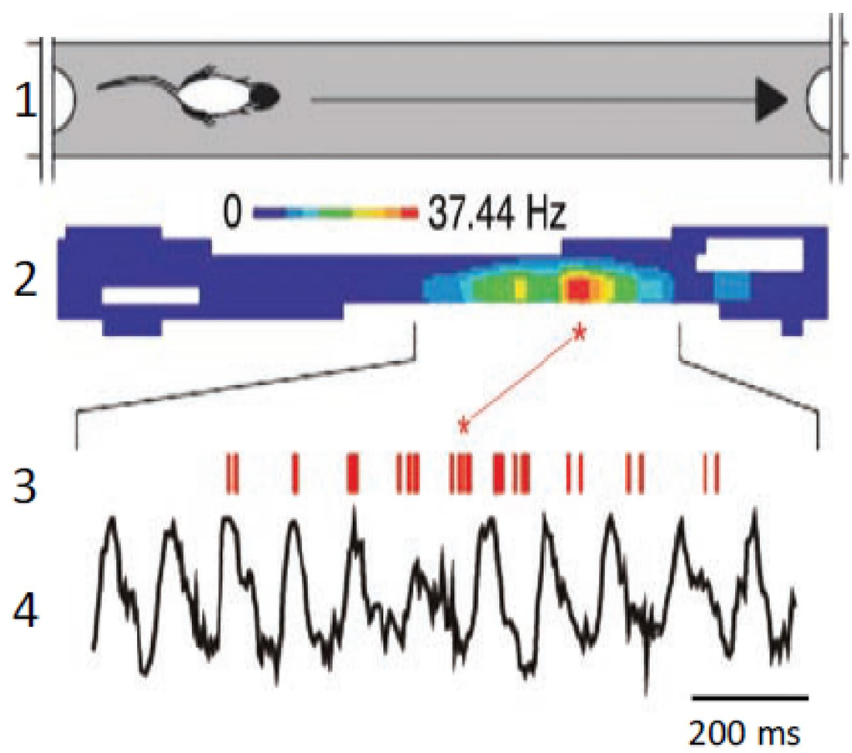

B

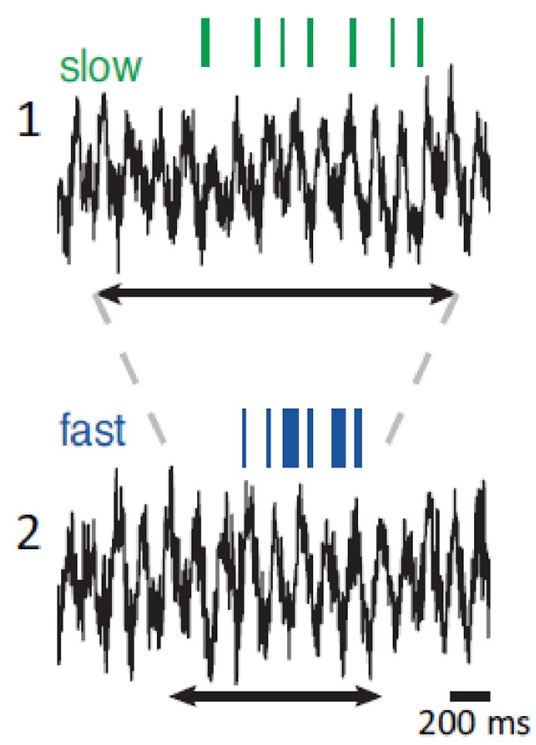

FIGURE 4 | Place neurons and $\theta$. (A1) Schematic diagram of rat traveling in the place field. (A2) Color coded display of place neuron firing rate in the place field. (A3,A4) Place neuron firings (red, upper) and field $\theta$ (lower). Note that the neuron displays phase precession and fires at a higher rate at a specific position in the place field. (B1) Place cell firing (green, upper) and corresponding field $\theta$ (lower) during slow locomotion (mean speed $31 \mathrm{~cm} / \mathrm{s})$. (B2) Same as (B1), but fast locomotion (mean speed $55 \mathrm{~cm} / \mathrm{s}$ ). The arrows indicate the time it takes the rat to cross the place field. Note that there is no change of field $\theta$ and that the neuron displays phase precession at both speeds but fires at a higher rate during the fast trial. (A) Modified from Buzsaki and Draguhn (2004); (B) modified from Geisler et al. (2007).

of action potentials per $\theta$ cycle increases, and the $\theta$ phase shifts proportionally, leaving the relationship between action potential phase and spatial position relatively invariant (Geisler et al., 2007; Pfeiffer and Foster, 2013). Place coding in the hippocampus requires sensory inputs providing environmental, self-motion, and place memory information, and effective spatial navigation involves remembering landmarks and goal location to plan navigation paths. Therefore, to continuously compute past, present, and future positions, the hippocampus compares distances and durations through a speed-dependent modulation, and these computations are independent on the behavioral task.

It is noteworthy that John O'Keefe, Edvard Moser, and May Brit Moser were awarded the Nobel Prize in 2014. O'Keeffe for his work on "place cells, " their relationship with hippocampal $\theta$ and spatial navigation, and Edvard and May Britt Moser for the identification of "grid cells" in the entorhinal cortex that are involved in positioning and pathfinding.

\section{INTERACTION OF THETA WITH GAMMA RHYTHMS}

In the hippocampus, $\theta$ and gamma $(\gamma)$ oscillations are the most prominent rhythms recorded in awake state or during REM sleep (Buzsaki, 2002; Cantero et al., 2003, 2004; Colgin, 2016). These oscillations can be observed in field potential recordings and are thought to transiently link distributed cell assemblies that are processing related information, a function that is important for network processes such as perception, attention, or memory (Singer, 1998; Buzsaki and Draguhn, 2004).

\section{$\gamma$ Frequency Bands in the Hippocampus}

Whereas in neocortical network $\gamma$ oscillations occur across a broad frequency band ranging from 30 to $140 \mathrm{~Hz}$, in the hippocampus, two different frequency bands are usually observed. Slow $\gamma$ ranges roughly from 25 to $60 \mathrm{~Hz}$ and fast $\gamma$ from 60 to $100 \mathrm{~Hz}$ (Bosman et al., 2014). These different frequency bands may route different input streams of information to the hippocampus. Slow $\gamma$ may facilitate transmission of inputs to CA1 from CA3 (Brun et al., 2002; Schomburg et al., 2014). Fast $\gamma$ may promote inputs from the entorhinal cortex that transmit ongoing spatial information (Brun et al., 2002; Hafting et al., 2005). Accordingly, fast $\gamma$ oscillations in CA1 were synchronized with fast $\gamma$ in medial entorhinal cortex, and slow $\gamma$ oscillations in CA1 were coherent with slow $\gamma$ in CA3 (Colgin et al., 2009). The firing properties of hippocampal neurons exhibited in each case may reflect different functions: memory retrieval during slow $\gamma$ and memory encoding during fast $\gamma$ oscillations (Figure 5).

\section{$\theta-\gamma$ Coupling During Memory Task Performance}

As indicated above, hippocampal $\theta$ activity is involved in forming new episodic memories, especially in encoding of location and time or the context of events (Lisman et al., 2017). During these active states, $\gamma$ oscillations are prominent and also participate in memory formation (Buzsaki and Draguhn, 2004). $\gamma$ oscillations are prominent in the entorhinal-hippocampal network during a variety of memory tasks in different species (Montgomery and Buzsáki, 2007; Sederberg et al., 2007; 


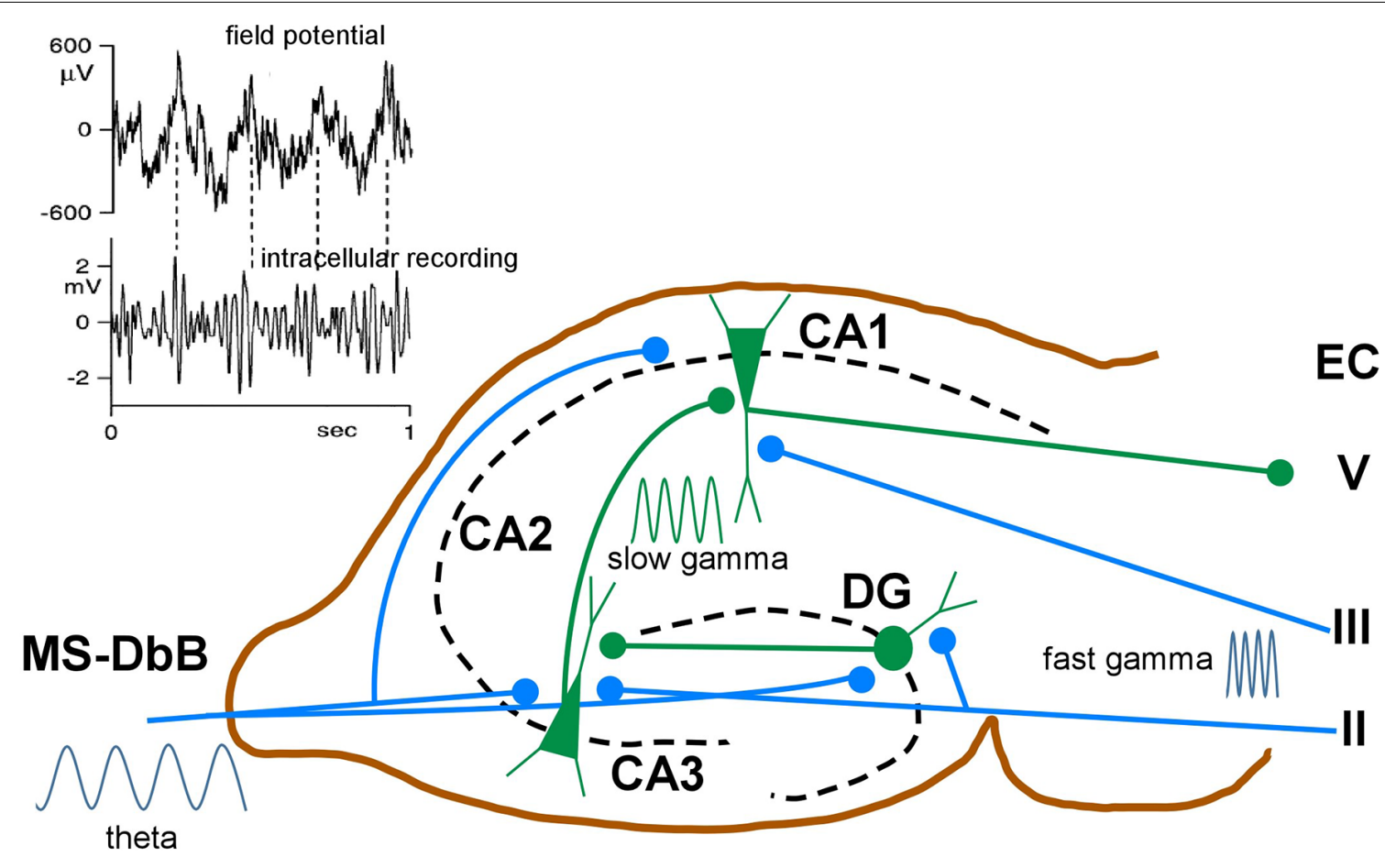

FIGURE 5 | Schematic diagram of neuronal circuits involved in theta-gamma $(\theta-\gamma)$ coupling. Blue traces indicate synaptic inputs from layers II to III of the enthorynal cortex (EC) and from the MS-DbB. The dentate gyrus (DG), CA1, CA3, and EC layer $V$ neuronal connections are also shown. $\theta-\gamma$ coupling in the hippocampus results from the convergence of $\theta$ inputs from the MS-DbB and fast $\gamma$ from the EC. Particularly, $\theta-\gamma$ coupling results in CA1 by the convergence of $\theta$ inputs from the MS-DbB and slow $\gamma$ from the CA3. The inset shows $\theta-\gamma$ interactions in the hippocampus as revealed by the CA1 field activity (upper) and band-pass filtered intracellular $\gamma$ activity (lower). Note phase locking between both rhythms ( $\theta-\gamma$ coupling) and the amplitude modulation of the intracellular $\gamma$; modified from Penttonen et al. (1998).

Jutras et al., 2009; López-Madrona et al., 2020). These authors suggest that successful memory performance requires coupling of $\gamma$ rhythms to particular phases of the hippocampal $\theta$ (termed $\theta-\gamma$ coupling). Hippocampal $\theta-\gamma$ coupling was observed during spatial memory processing (Penttonen et al., 1998; Buzsaki and Moser, 2013) and has been shown to support the induction of LTP (Jensen and Lisman, 1996; Buzsaki, 2002; Vertes, 2005).

$\theta-\gamma$ coupling is modulated during exploration and memoryguided behaviors. In mice solving a mnemonic task, CA1 $\gamma$ oscillations were more strongly phase locked to $\theta$ than in control periods (Tort et al., 2008). Similarly, rats learning to associate contexts with the location of food reward show an increase in $\theta-\gamma$ coupling during the learning progression (Lisman and Jensen, 2013). In a word recognition paradigm in humans, $\theta-\gamma$ coupling was selectively enhanced when patients successfully remembered previously presented words (Mormann et al., 2005). In agreement with that, Axmacher and colleagues, using intracranial EEG recordings showed $\theta-\gamma$ coupling in the hippocampus during working memory retention in a working memory task, and the strength of this coupling predicted individual working memory performance (Axmacher et al., 2010).

In rodents, $20-40 \mathrm{~Hz}$ oscillations in CA1 became more tightly locked to the $\theta$ phase as animals learned odor-place associations, suggesting that $\theta-\gamma$ coupling may play an important role in cued memory retrieval (Igarashi et al., 2014). In another study, $\gamma$ power in CA1 increased in a delayed spatial alternation task when animals needed to remember which side to choose (Takahashi et al., 2014). $\theta-\gamma$ coupling was mainly observed during episodes of both active wake and REM sleep, with the highest level of coupling observed during REM sleep (Bandarabadi et al., 2019). Taken together, these results support the hypothesis that $\theta-\gamma$ coupling facilitates transfer of spatial information from the enthorinal cortex to CA1 (Brun et al., 2002; Hafting et al., 2005; Colgin et al., 2009).

It has been reported that inputs from the enthorinal cortex and CA 3 arrive in CA 1 at specific phases of the $\theta$ cycle (Hasselmo et al., 2002; Colgin et al., 2009). LTP in CA1 is most easily induced at a particular $\theta$ phase, which corresponds to the phase when enthorinal cortex input is maximal (Huerta and Lisman, 1995). Activating $\gamma$-modulated cell assemblies at a particular $\theta$ phase may allow the network to produce a more powerful output by ensuring that distributed cells fire closely in time (Bragin et al., 1997; Tort et al., 2008). $\theta-\gamma$ coupling may allow the hippocampal-entorhinal network to temporally organize sequences of events within each $\theta$ cycle, raising the possibility that $\theta-\gamma$ interactions are a critical component of mnemonic operations (Bragin et al., 1997). $\theta-\gamma$ coupling leads to a precise temporal coordination of spikes of multiple neurons and is therefore likely to contribute to circuital functions such as phase coding or spike-timing-dependent plasticity (Markram et al., 1997; Abbott and Nelson, 2000). 


\section{Theta-Gamma Coupling in Degenerative Pathologies}

Taken together, the above results strongly suggest that $\theta-\gamma$ coupling is vital in learning and memory processes, and consequently, its loss may be at the base of pathologies. Working memory deficits are common among individuals with Alzheimer's dementia (AD) or mild cognitive impairment (MCI). The origin of these deficits has long been thought to be due to hippocampal and enthorinal cortical dysfunctions, although atrophy of MS-DbB also occurs in AD (Cantero et al., 2020). AD and MCI patients demonstrate the lowest level of $\theta-\gamma$ coupling in a verbal working memory task in comparison with healthy participants (Goodman et al., 2018). Similar findings have been observed in animal models of $\mathrm{AD}$, which show a decreased $\theta-\gamma$ coupling (Zhang et al., 2016; Bazzigaluppi et al., 2018) that arises before amyloid beta accumulation (Goutagny and Krantic, 2013; Iaccarino et al., 2016). An impairment of $\theta-\gamma$ coupling that increases paralleling the progression of the MCI has been recently reported in human patients (Musaeus et al., 2020). These findings suggest that $\theta-\gamma$ coupling is critical for proper cognitive functioning and may therefore serve as a progression marker in degenerative diseases.

Place cells in the hippocampus fire action potentials in specific spatial locations (O'Keefe and Dostrovsky, 1971), whereas grid cells in the medial entorhinal cortex fire in a highly organized spatial pattern across an environment (Fyhn et al., 2004; Hafting et al., 2005). Patients with $\mathrm{AD}$ and other dementia-spectrum disorders exhibit profound disruption in spatial navigation and memory, even at very early stages of the disease (Hort et al., 2007; Allison et al., 2016). At a pathological level, misfolded tau deposition typically occurs first in the entorhinal cortex and hippocampus (Rubio et al., 2008; Cantero et al., 2011; LlorensMartin et al., 2014) and reduce grid cell activity (Pooler et al., 2014; Ridler et al., 2020). These data correlate with human imaging studies, which suggest deficits in grid-cell-like activity in the entorhinal cortices of people at genetic risk of developing AD (Kunz et al., 2015).

\section{REFERENCES}

Abbott, L. F., and Nelson, S. B. (2000). Synaptic plasticity: taming the beast. Nat. Neurosci. 3, 1178-1183. doi: 10.1038/81453

Adey, W. R. (1967). Hippocwmpal states and functional relations with corticosubcortical systems in attention and learning. Prog. Brain Res. 27, 228-245. doi: 10.1016/s0079-6123(08)63102-7

Ahmed, O. J., and Mehta, M. R. (2012). Running speed alters the frequency of hippocampal gamma oscillations. J. Neurosci. 32, 7373-7383. doi: 10.1523/JNEUROSCI.5110-11.2012

Allison, S. L., Fagan, A. M., Morris, J. C., and Head, D. (2016). Spatial navigation in preclinical Alzheimer's disease. J. Alzheimers Dis. 52, 77-90. doi: 10.3233/JAD150855

Alonso, A., and Garcia-Austt, E. (1987). Neuronal sources of theta rhythm in the entorhinal cortex of the rat. II. Phase relations between unit discharges and theta field potentials. Exp. Brain Res. 67, 502-509. doi: 10.1007/BF00 247283

Alonso, A., Gaztelu, J. M., Buno, W., Jr., and Garcia-Austt, E. (1987). Cross-correlation analysis of septohippocampal neurons during theta-rhythm. Brain Res. 413, 135-146. doi: 10.1016/0006-8993(87) 90162-4

\section{CONCLUDING REMARKS}

In the brain, information is represented by the activity of ensembles of neurons rather than by single cells, coordinating their activity to support complex cognitive processes and creating functional neural networks (Singer, 1998). An efficient way to assure transient synchronization between neuronal ensembles is the entrainment of neuronal groups into oscillatory activities. Oscillations may facilitate neuronal synchronization and synaptic plasticity, playing a key role in long-range communication between brain regions. In this review, we underscore that the $\theta$ rhythm results from complex interactions between circuital and intrinsic properties of MS-DbB and hippocampal neurons and that it plays a crucial role in cognitive processes such as learning and memory, and in the control of complex behaviors.

\section{AUTHOR CONTRIBUTIONS}

AN and WB conceived and wrote all aspects of this review. All authors contributed to the article and approved the submitted version.

\section{FUNDING}

This work was supported by the Spanish Ministry of Science and Innovation Grant (PID2019-107809RB-I00).

\section{ACKNOWLEDGMENTS}

We would like to acknowledge the work, teachings, and dedication of Professor Elio Garcia Austt who introduced us to the world of electrophysiology and with whom we collaborated in an important number of the publications included in this review. We would also like to thank Professor José Luís Cantero for his interesting comments.

Alonso, A., and Llinas, R. (1989). Subthreshold Na dependent theta-like rhythmicity in stellate cells of entorhinal cortex layer II. Nature 342, 175-177. doi: $10.1038 / 342175 \mathrm{a} 0$

Andersen, P., and Eccles, J. (1962). Inhibitory phasing of neuronal discharge. Nature 196, 645-647. doi: 10.1038/196645a0

Antic, S. D., Zhou, W. L., Moore, A. R., Short, S. M., and Ikonomu, K. D. (2010). The decade of the dendritic NMDA spike. J. Neurosci. Res. 88, 2991-3001. doi: $10.1002 /$ jnr.22444

Aronov, D., Nevers, R., and Tank, D. W. (2017). Mapping of a non-spatial dimension by the hippocampal-entorhinal circuit. Nature 543, 719-722. doi: $10.1038 /$ nature 21692

Axmacher, N., Henseler, M. M., Jensen, O., Weinreich, I., Elger, C. E., and Fell, J. (2010). Cross-frequency coupling supports multi-item working memory in the human hippocampus. Proc. Natl. Acad. Sci. U S A 107, 3228-3233. doi: 10.1073/pnas.0911531107

Bandarabadi, M., Boyce, R., Gutierrez Herrera, C., Bassetti, C. L., Williams, S., Schindler, K., et al. (2019). Dynamic modulation of theta-gamma coupling during rapid eye movement sleep. Sleep 42:zsz182. doi: 10.1093/sleep/zsz182

Barbizet, J. (1963). Defect of memorizing of hippocampal-mammillary origin: a review. J. Neurol. Neurosurg. Psychiatry 26, 127-135. doi: 10.1136/jnnp. 26.2.127 
Barrenechea, C., Pedemonte, M., Nunez, A., and Garcia-Austt, E. (1995). In vivo intracellular recordings of medial septal and diagonal band of Broca neurons: relationships with theta rhythm. Exp. Brain Res. 103, 31-40. doi: 10.1007/BF00241962

Barrio, L. C., and Buño, W. (1990). Temporal correlations in sensory-synaptic interactions: example in crayfish stretch receptors. J. Neurophysiol. 63, 1520-1528. doi: 10.1152/jn.1990.63.6.1520

Bazzigaluppi, P., Beckett, T. L., Koletar, M. M., Lai, A. Y., Joo, I. L., Brown, M. E., et al. (2018). Early-stage attenuation of phase-amplitude coupling in the hippocampus and medial prefrontal cortex in a transgenic rat model of Alzheimer's disease. J. Neurochem. 144, 669-679. doi: 10.1111/jnc.14136

Bender, F., Gorbati, M., Cadavieco, M. C., Denisova, N., Gao, X., Holman, C., et al. (2015). Theta oscillations regulate the speed of locomotion via a hippocampus to lateral septum pathway. Nat. Commun. 6:8521. doi: 10.1038/ncomms9521

Bland, B. H., and Colom, L. V. (1993). Extrinsic and intrinsic properties underlying oscillation and synchrony in limbic cortex. Prog. Neurobiol. 41, 157-208. doi: 10.1016/0301-0082(93)90007-f

Bland, B. H., Colom, L. V., Konopacki, J., and Roth, S. H. (1988). Intracellular records of carbachol-induced theta rhythm in hippocampal slices. Brain Res. 447, 364-368. doi: 10.1016/0006-8993(88)91141-9

Bland, B. H., Declerck, S., Jackson, J., Glasgow, S., and Oddie, S. (2007). Septohippocampal properties of N-methyl-D-aspartate-induced theta-band oscillation and synchrony. Synapse 61, 185-197. doi: 10.1002/syn.20357

Bonansco, C., and Buño, W. (2003). Cellular mechanisms underlying the rhythmic bursts induced by NMDA microiontophoresis at the apical dendrites of CA1 pyramidal neurons. Hippocampus 13, 150-163. doi: 10.1002/hipo. 10067

Bonansco, C., Gonzalez de la Vega, A., Gonzalez Alegre, P., Borde, M., GarcaSegura, L. M., and Buño, W. (2002). Tetanic stimulation of schaffer collaterals induces rhythmic bursts via NMDA receptor activation in rat CA1 pyramidal neurons. Hippocampus 12, 434-446. doi: 10.1002/hipo.10023

Bosman, C. A., Lansink, C. S., and Pennartz, C. M. (2014). Functions of gamma-band synchronization in cognition: from single circuits to functional diversity across cortical and subcortical systems. Eur. J. Neurosci. 39, 1982-1999. doi: 10.1111/ejn.12606

Boyce, R., Glasgow, S. D., Williams, S., and Adamantidis, A. (2016). Causal evidence for the role of REM sleep theta rhythm in contextual memory consolidation. Science 352, 812-816. doi: 10.1126/science.aad5252

Bragin, A., Penttonen, M., and Buzsáki, G. (1997). Termination of epileptic afterdischarge in the hippocampus. J. Neurosci. 17, 2567-2579. doi: 10.1523/JNEUROSCI.17-07-02567.1997

Brazhnik, E. S., Vinogradova, O. S., and Karanov, A. M. (1985). Frequency modulation of neuronal theta-bursts in rabbit's septum by low-frequency repetitive stimulation of the afferent pathways. Neuroscience 14, 501-508. doi: 10.1016/0306-4522(85)90305-7

Brown, E. N., Frank, L. M., Tang, D., Quirk, M. C., and Wilson, M. A. (1998). A statistical paradigm for neural spike train decoding applied to position prediction from ensemble firing patterns of rat hippocampal place cells. J. Neurosci. 18, 7411-7425. doi: 10.1523/JNEUROSCI.18-18-07411.1998

Brun, V. H., Otnass, M. K., Molden, S., Steffenach, H. A., Witter, M. P., Moser, M. B., et al. (2002). Place cells and place recognition maintained by direct entorhinal-hippocampal circuitry. Science 296, 2243-2246. doi: 10.1126/science.1071089

Buño, W., Jr., Bustamante, J., and Fuentes, J. (1984). White noise analysis of pacemaker-response interactions and non-linearities in slowly adapting crayfish stretch receptor. J. Physiol. 350, 55-80. doi: 10.1111/nph.17283

Buño, W., Garcia-Sanchez, J. L., and Garcia-Austt, E. (1978). Reset of hippocampal rhythmical activities by afferent stimulation. Brain Res. Bull. 3, 21-28. doi: 10.1111/nph.17283

Buño, W., Jr., and Velluti, J. C. (1977). Relationships of hippocampal theta cycles with bar pressing during self-stimulation. Physiol. Behav. 19, 615-621. doi: 10.1111/nph.17283

Burgess, S. E., Gardell, L. R., Ossipov, M. H., Malan, T. P., Jr., Vanderah, T. W., Lai, J., et al. (2002). Time-dependent descending facilitation from the rostral ventromedial medulla maintains, but does not initiate, neuropathic pain. J. Neurosci. 22, 5129-5136. doi: 10.1523/JNEUROSCI.22-12-05129.2002

Buzsaki, G. (2002). Theta oscillations in the hippocampus. Neuron 33, 325-340. doi: 10.1016/s0896-6273(02)00586-x
Buzsaki, G. (2020). The brain-cognitive behavior problem: a retrospective. eNeuro 7:ENEURO.0069-20.2020. doi: 10.1523/ENEURO.0069-20.2020

Buzsaki, G., and Draguhn, A. (2004). Neuronal oscillations in cortical networks. Science 304, 1926-1929. doi: 10.1126/science.1099745

Buzsaki, G., and Eidelberg, E. (1983). Phase relations of hippocampal projection cells and interneurons to theta activity in the anesthetized rat. Brain Res. 266, 334-339. doi: 10.1016/0006-8993(83)90665-0

Buzsaki, G., Grastyan, E., Tveritskaya, I. N., and Czopf, J. (1979). Hippocampal evoked potentials and EEG changes during classical conditioning in the rat. Electroencephalogr. Clin. Neurophysiol. 47, 64-74. doi: 10.1016/00134694(79)90033-6

Buzsaki, G., and Moser, E. I. (2013). Memory, navigation and theta rhythm in the hippocampal-entorhinal system. Nat. Neurosci. 16, 130-138. doi: 10.1038/ nn.3304

Cantero, J. L., Atienza, M., Lage, C., Zaborszky, L., Vilaplana, E., Lopez-Garcia, S., et al. (2020). Atrophy of basal forebrain initiates with tau pathology in individuals at risk for Alzheimer's disease. Cereb. Cortex 30, 2083-2098. doi: 10.1093/cercor/bhz224

Cantero, J. L., Atienza, M., Madsen, J. R., and Stickgold, R. (2004). Gamma EEG dynamics in neocortex and hippocampus during human wakefulness and sleep. NeuroImage 22, 1271-1280. doi: 10.1016/j.neuroimage.2004.03.014

Cantero, J. L., Atienza, M., Stickgold, R., Kahana, M. J., Madsen, J. R., and Kocsis, B. (2003). Sleep-dependent theta oscillations in the human hippocampus and neocortex. J. Neurosci. 23, 10897-10903. doi: 10.1523/JNEUROSCI.23-34-10897.2003

Cantero, J. L., Moreno-Lopez, B., Portillo, F., Rubio, A., Hita-Yanez, E., and Avila, J. (2011). Role of tau protein on neocortical and hippocampal oscillatory patterns. Hippocampus 21, 827-834. doi: 10.1002/hipo.20798

Cei, A., Girardeau, G., Drieu, C., Kanbi, K. E., and Zugaro, M. (2014). Reversed theta sequences of hippocampal cell assemblies during backward travel. Nat. Neurosci. 17, 719-724. doi: 10.1038/nn.3698

Cheng, Q., and Yakel, J. L. (2015). The effect of alpha7 nicotinic receptor activation on glutamatergic transmission in the hippocampus. Biochem. Pharmacol. 97, 439-444. doi: 10.1016/j.bcp.2015.07.015

Cherubini, E., and Miles, R. (2015). The CA3 region of the hippocampus: how is it? What is it for? How does it do it? Front. Cell. Neurosci. 9:19. doi: 10.3389/fncel. 2015.00019

Cobb, S. R., Buhl, E. H., Halasy, K., Paulse, O., and Somogyi, P. (1995). Synchronization of neuronal activity in hippocampus by individual GABAergic interneurons. Nature 378, 75-78. doi: 10.1038/378075a0

Colgin, L. L. (2016). Rhythms of the hippocampal network. Nat. Rev. Neurosci. 17, 239-249. doi: 10.1038/nrn.2016.21

Colgin, L. L., Denninger, T., Fyhn, M., Hafting, T., Bonnevie, T., Jensen, O., et al. (2009). Frequency of gamma oscillations routes flow of information in the hippocampus. Nature 462, 353-357. doi: 10.1038/nature08573

Colom, L. V., Castaneda, M. T., Reyna, T., Hernandez, S., and Garrido-Sanabria, E. (2005). Characterization of medial septal glutamatergic neurons and their projection to the hippocampus. Synapse 58, 151-164. doi: 10.1002/syn. 20184

Csicsvari, J., Hirase, H., Czurko, A., Mamiya, A., and Buzsaki, G. (1999). Fast network oscillations in the hippocampal CAl region of the behaving rat. J. Neurosci. 19:RC20. doi: 10.1523/JNEUROSCI.19-16j0001.1999

Descarries, L., Krnjevic, K., and Steriade, M. (2004). Acetylcholine in the cerebral cortex. Prog. Brain Res. 145, 179-196. doi: 10.1016/S0079-6123(03) 45013-9

Desikan, S., Koser, D. E., Neitz, A., and Monyer, H. (2018). Target selectivity of septal cholinergic neurons in the medial and lateral entorhinal cortex. Proc. Natl. Acad. Sci. U S A 115, E2644-E2652. doi: 10.1073/pnas.1716 531115

Dickson, C. T., Magistretti, J., Shalinsky, M., Hamam, B., and Alonso, A. (2000) Oscillatory activity in entorhinal neurons and circuits. Mechanisms and function. Ann. N Y Acad. Sci. 911, 127-150. doi: 10.1111/j.1749-6632.2000. tb06723.x

Domínguez, S., Fernández de Sevilla, D., and Buño, W. (2014). Postsynaptic activity reverses the sign of the acetylcholine-induced long-term plasticity of GABAA inhibition. Proc. Natl. Acad. Sci. U S A 111, E2741-2750. doi: 10.1073/pnas.1321777111 
Drever, B. D., Riedel, G., and Platt, B. (2011). The cholinergic system and hippocampal plasticity. Behav. Brain Res. 221, 505-514. doi: 10.1016/j.bbr. 2010.11.037

Dudar, J. D. (1977). The role of the septal nuclei in the release of acetyl-choline from the rabbit cerebral cortex and dorsal hippocampus and the effect of atropine. Brain Res. 129, 237-246. doi: 10.1016/0006-8993(77)90004-x

Dusek, J. A., and Eichenbaum, H. (1998). The hippocampus and transverse patterning guided by olfactory cues. Behav. Neurosci. 112, 762-771. doi: 10.1037/0735-7044.112.4.762

Fernández de Sevilla, D. F., Cabezas, C., de Prada, A. N., Sanchez-Jimenez, A., and Buño, W. (2002). Selective muscarinic regulation of functional glutamatergic Schaffer collateral synapses in rat CA1 pyramidal neurons. J. Physiol. 545, 51-63. doi: 10.1113/jphysiol.2002.029165

Fernández de Sevilla, D., Garduno, J., Galvan, E., and Buno, W. (2006). Calciumactivated afterhyperpolarizations regulate synchronization and timing of epileptiform bursts in hippocampal CA3 pyramidal neurons. J. Neurophysiol. 96, 3028-3041. doi: 10.1152/jn.00434.2006

Fernández de Sevilla, D., Nunez, A., and Buno, W. (2020). Muscarinic receptors, from synaptic plasticity to its role in network activity. Neuroscience 456, 60-70. doi: 10.1016/j.neuroscience.2020.04.005

Freund, T. F. (1992). GABAergic septal and serotonergic median raphe afferents preferentially innervate inhibitory interneurons in the hippocampus and dentate gyrus. Epilepsy Res. Suppl. 7, 79-91.

Freund, T. F., and Buzsaki, G. (1996). Interneurons of the hippocampus. Hippocampus 6, 347-470. doi: 10.1002/(SICI)1098-1063(1996)6:4<347::AID$\mathrm{HIPO} 1>3.0 . \mathrm{CO} ; 2-\mathrm{I}$

Frotscher, M., and Léránth, C. (1985). Cholinergic innervation of the rat hippocampus as revealed by choline acetyltransferase immunocytochemistry: a combined light and electron microscopic study. J. Comp. Neurol. 239, 237-246. doi: 10.1002/cne.902390210

Fuhrmann, F., Justus, D., Sosulina, L., Kaneko, H., Beutel, T., Friedrichs, D., et al. (2015). Locomotion, theta oscillations and the speed-correlated firing of hippocampal neurons are controlled by a medial septal glutamatergic circuit. Neuron 86, 1253-1264. doi: 10.1016/j.neuron.2015.05.001

Fujita, Y. (1991). Impulse conduction in CA1 apical dendrites of rabbit hippocampus: its possible implications in normal and abnormal activities. J. Physiol. 443, 335-353. doi: 10.1113/jphysiol.1991. sp018836

Fyhn, M., Molden, S., Witter, M. P., Moser, E. I., and Moser, M. B. (2004). Spatial representation in the entorhinal cortex. Science 305, 1258-1264. doi: 10.1126/science.1099901

Gage, F. H., Olton, D. S., and Bolanowski, D. (1978). Activity, reactivity and dominance following septal lesions in rats. Behav. Biol. 22, 203-210. doi: 10.1016/s0091-6773(78)92230-7

Gangadharan, G., Shin, J., Kim, S. W., Kim, A., Paydar, A., Kim, D. S., et al. (2016). Medial septal GABAergic projection neurons promote object exploration behavior and type 2 theta rhythm. Proc. Natl. Acad. Sci. U S A 113, 6550-6555. doi: 10.1073/pnas.1605019113

García-Muñoz, A., Barrio, L. C., and Buño, W. (1993). Membrane potential oscillations in CA1 hippocampal pyramidal neurons in vitro: intrinsic rhythms and fluctuations entrained by sinusoidal injected current. Exp. Brain Res. 97, 325-333. doi: 10.1007/BF00228702

García-Sánchez, J. L., Buño, W., Jr., Fuentes, J., and Garcií-Austt, E. (1978). Nonrhythmical hippocampal units, theta rhythm and afferent stimulation. Brain Res. Bull. 3, 213-219. doi: 10.1016/0361-9230(78)90116-8

Gaztelu, J. M., and Buño, W. (1982). Septo-hippocampal relationships during EEG theta rhythm. Electroenceph. Clin. Neurophysiol. 54, 375-387. doi: 10.1016/0013-4694(82)90201-2

Geisler, C., Robbe, D., Zugaro, M., Sirota, A., and Buzsáki, G. (2007). Hippocampal place cell assemblies are speed-controlled oscillators. Proc. Natl. Acad. Sci. U S A 104, 8149-8154. doi: 10.1073/pnas.0610121104

Givens, B. (1996). Stimulus-evoked resetting of the dentate theta rhythm: relation to working memory. Neuroreport 8, 159-163. doi: 10.1097/00001756199612200-00032

Goodman, M. S., Kumar, S., Zomorrodi, R., Ghazala, Z., Cheam, A. S. M., Barr, M. S., et al. (2018). Theta-gamma coupling and working memory in Alzheimer's dementia and mild cognitive impairment. Front. Aging Neurosci. 10:101. doi: 10.3389/fnagi.2018.00101
Goutagny, R., and Krantic, S. (2013). Hippocampal oscillatory activity in Alzheimer's disease: toward the identification of early biomarkers? Aging Dis. 4, 134-140.

Gray, R., Rajan, A. S., Radcliffe, K. A., Yakehiro, M., and Dani, J. A. (1996). Hippocampal synaptic transmission enhanced by low concentrations of nicotine. Nature 383, 713-716. doi: 10.1038/383713a0

Green, J. D., and Arduini, A. A. (1954). Hippocampal electrical activity in arousal. J. Neurophysiol. 17, 533-557. doi: 10.1152/jn.1954.17.6.533

Griguoli, M., and Cherubini, E. (2012). Regulation of hippocampal inhibitory circuits by nicotinic acetylcholine receptors. J. Physiol. 590, 655-666. doi: 10.1113/jphysiol.2011.220095

Griguoli, M., Maul, A., Nguyen, C., Giorgetti, A., Carloni, P., and Cherubini, E. (2010). Nicotine blocks the hyperpolarization-activated current Ih and severely impairs the oscillatory behavior of oriens-lacunosum moleculare interneurons. J. Neurosci. 30, 10773-10783. doi: 10.1523/JNEUROSCI.2446-10.2010

Gu, Z., Alexander, G. M., Dudek, S. M., and Yakel, J. L. (2017). Hippocampus and entorhinal cortex recruit cholinergic and NMDA receptors separately to generate hippocampal theta oscillations. Cell Rep. 21, 3585-3595. doi: 10.1016/j. celrep.2017.11.080

Hafting, T., Fyhn, M., Molden, S., Moser, M. B., and Moser, E. I. (2005) Microstructure of a spatial map in the entorhinal cortex. Nature 436, 801-806. doi: $10.1038 /$ nature 03721

Hanada, Y., Hallworth, N. E., Szgatti, T. L., Scarlett, D., and Bland, B. H. (1999). Distribution and analysis of hippocampal theta-related cells in the pontine region of the urethane-anesthetized rat. Hippocampus 9, 288-302. doi: 10.1002/(SICI)1098-1063(1999)9:3<288::AID-HIPO8>3.0.CO;2-A

Hangya, B., Borhegyi, Z., Szilagyi, N., Freund, T. F., and Varga, V. (2009). GABAergic neurons of the medial septum lead the hippocampal network during theta activity. J. Neurosci. 29, 8094-8102. doi: 10.1523/JNEUROSCI. 5665-08.2009

Harvey, C. D., Collman, F., Dombeck, D. A., and Tank, D. W. (2009). Intracellular dynamics of hippocampal place cells during virtual navigation. Nature 461, 941-946. doi: 10.1038/nature08499

Hasselmo, M. E., Bodelon, C., and Wyble, B. P. (2002). A proposed function for hippocampal theta rhythm: separate phases of encoding and retrieval enhance reversal of prior learning. Neural Comput. 14, 793-817. doi: 10.1162/089976602317318965

Hort, J., Laczo, J., Vyhnalek, M., Bojar, M., Bures, J., and Vlcek, K. (2007). Spatial navigation deficit in amnestic mild cognitive impairment. Proc. Natl. Acad. Sci. US A 104, 4042-4047. doi: 10.1073/pnas.0611314104

Huerta, P. T., and Lisman, J. E. (1995). Bidirectional synaptic plasticity induced by a single burst during cholinergic theta oscillation in CA1 in vitro. Neuron 15 , 1053-1063. doi: 10.1016/0896-6273(95)90094-2

Huh, C. Y., Goutagny, R., and Williams, S. (2010). Glutamatergic neurons of the mouse medial septum and diagonal band of Broca synaptically drive hippocampal pyramidal cells: relevance for hippocampal theta rhythm. J. Neurosci. 30, 15951-15961. doi: 10.1523/JNEUROSCI.3663-10.2010

Iaccarino, H. F., Singer, A. C., Martorell, A. J., Rudenko, A., Gao, F., Gillingham, T. Z., et al. (2016). Gamma frequency entrainment attenuates amyloid load and modifies microglia. Nature 540, 230-235. doi: 10.1038/nature20587

Igarashi, K. M., Lu, L., Colgin, L. L., Moser, M. B., and Moser, E. I. (2014). Coordination of entorhinal-hippocampal ensemble activity during associative learning. Nature 510, 143-147. doi: 10.1038/nature13162

Jackson, J., Dickson, C. T., and Bland, B. H. (2008). Median raphe stimulation disrupts hippocampal theta via rapid inhibition and state-dependent phase reset of theta-related neural circuitry. J. Neurophysiol. 99, 3009-3026. doi: $10.1152 /$ jn.00065.2008

Jensen, O., and Lisman, J. E. (1996). Theta/gamma networks with slow NMDA channels learn sequences and encode episodic memory: role of NMDA channels in recall. Learn. Mem. 3, 264-278. doi: 10.1101/lm.3.2-3.264

Jensen, O., and Lisman, J. E. (2000). Position reconstruction from an ensemble of hippocampal place cells: contribution of theta phase coding. J. Neurophysiol. 83, 2602-2609. doi: 10.1152/jn.2000.83.5.2602

Joshi, A., Salib, M., Viney, T. J., Dupret, D., and Somogyi, P. (2017). Behavior-dependent activity and synaptic organization of septo-hippocampal GABAergic neurons selectively targeting the hippocampal CA3 area. Neuron 96, 1342.e5-1357.e5. doi: 10.1016/j.neuron.2017.10.033 
Joshi, A., and Somogyi, P. (2020). Changing phase relationship of the stepping rhythm to neuronal oscillatory theta activity in the septo-hippocampal network of mice. Brain Struct. Funct. 225, 871-879. doi: 10.1007/s00429-020-02031-8

Jung, R., and Kornmüller, A. (1938). Eine methodik der ableitung lokalisierter potential schwankingen aus subcorticalen hirnyebieten. Arch. Psychiat. Neruenkr. 109, 1-30.

Jutras, M. J., Fries, P., and Buffalo, E. A. (2009). Gamma-band synchronization in the macaque hippocampus and memory formation. J. Neurosci. 29, 12521-12531. doi: 10.1523/JNEUROSCI.0640-09.2009

Kamondi, A., Acsady, L., Wang, X. J., and Buzsaki, G. (1998). Theta oscillations in somata and dendrites of hippocampal pyramidal cells in vivo: activitydependent phase-precession of action potentials. Hippocampus 8, 244-261. doi: 10.1002/(SICI) 1098-1063(1998)8:3<244::AID-HIPO7>3.0.CO;2-J

Kazmierska, P., and Konopacki, J. (2013). Development of NMDA-induced theta rhythm in hippocampal formation slices. Brain Res. Bull. 98, 93-101. doi: 10.1016/j.brainresbull.2013.07.010

Kerren, C., Linde-Domingo, J., Hanslmayr, S., and Wimber, M. (2018). An optimal oscillatory phase for pattern reactivation during memory retrieval. Curr. Biol. 28, 3383.e6-3392.e6. doi: 10.1016/j.cub.2018. 08.065

Khakpai, F., Nasehi, M., and Zarrindast, M. R. (2016). The role of NMDA receptors of the medial septum and dorsal hippocampus on memory acquisition. Pharmacol. Biochem. Behav. 143, 18-25. doi: 10.1016/j.pbb.2016. 01.003

Klausberger, T., Magill, P. J., Marton, L. F., Roberts, J. D., Cobden, P. M., Buzsaki, G., et al. (2003). Brain-state- and cell-type-specific firing of hippocampal interneurons in vivo. Nature 421, 844-848. doi: $10.1038 /$ nature 01374

Klausberger, T., and Somogyi, P. (2008). Neuronal diversity and temporal dynamics: the unity of hippocampal circuit operations. Science 321, 53-57. doi: $10.1126 /$ science.1149381

Kocsis, B., and Vertes, R. P. (1994). Characterization of neurons of the supramammillary nucleus and mammillary body that discharge rhythmically with the hippocampal theta rhythm in the rat. J. Neurosci. 14, 7040-7052. doi: 10.1523/JNEUROSCI.14-11-07040.1994

Konopacki, J., Bland, B. H., MacIver, M. B., and Roth, S. H. (1987). Cholinergic theta rhythm in transected hippocampal slices: independent CA1 and dentate generators. Brain Res. 436, 217-222. doi: 10.1016/0006-8993(87)91664-7

Konopacki, J., Bocian, R., Kowalczyk, T., and Klos-Wojtczak, P. (2014). The electrical coupling and the hippocampal formation theta rhythm in rats. Brain Res. Bull. 107, 1-17. doi: 10.1016/j.brainresbull.2014.04.007

Kragel, J. E., VanHaerents, S., Templer, J. W., Schuele, S., Rosenow, J. M., Nilakantan, A. S., et al. (2020). Hippocampal theta coordinates memory processing during visual exploration. eLife 9:e52108. doi: 10.7554/eLife.52108

Kramis, R., Vanderwolf, C. H., and Bland, B. H. (1975). Two types of hippocampal rhythmical slow activity in both the rabbit and the rat: relations to behavior and effects of atropine, diethyl ether, urethane and pentobarbital. Exp. Neurol. 49, 58-85. doi: 10.1016/0014-4886(75)90195-8

Kunz, L., Schroder, T. N., Lee, H., Montag, C., Lachmann, B., Sariyska, R., et al. (2015). Reduced grid-cell-like representations in adults at genetic risk for Alzheimer's disease. Science 350, 430-433. doi: 10.1126/science.aac8128

Lakatos, P., Gross, J., and Thut, G. (2019). A new unifying account of the roles of neuronal entrainment. Curr. Biol. 29, R890-R905. doi: 10.1016/j.cub.2019. 07.075

Lerma, J., and García-Austt, E. (1985). Hippocampal theta rhythm during paradoxical sleep. Effects of afferent stimuli and phase relationships with phasic events. Electroencephalogr. Clin. Neurophysiol. 60, 46-54. doi: 10.1016/00134694(85) $90950-2$

Leung, L. W., and Desborough, K. A. (1988). APV, an N-methyl-D-aspartate receptor antagonist, blocks the hippocampal theta rhythm in behaving rats. Brain Res. 463, 148-152. doi: 10.1016/0006-8993(88)90538-0

Leung, L. S., and Shen, B. (2004). Glutamatergic synaptic transmission participates in generating the hippocampal EEG. Hippocampus 14, 510-525. doi: 10.1002/hipo.10199

Li, S., Topchiy, I., and Kocsis, B. (2007). The effect of atropine administered in the medial septum or hippocampus on high- and low-frequency theta rhythms in the hippocampus of urethane anesthetized rats. Synapse 61, 412-419. doi: $10.1002 /$ syn.20388
Lisman, J. (2017). Glutamatergic synapses are structurally and biochemically complex because of multiple plasticity processes: long-term potentiation, long-term depression, short-term potentiation and scaling. Philos. Trans. $R$. Soc. Lond. B Biol. Sci. 372:20160260. doi: 10.1098/rstb.2016.0260

Lisman, J., Buzsaki, G., Eichenbaum, H., Nadel, L., Ranganath, C., and Redish, A. D. (2017). Viewpoints: how the hippocampus contributes to memory, navigation and cognition. Nat. Neurosci. 20, 1434-1447. doi: 10.1038/nn.4661

Lisman, J. E., and Jensen, O. (2013). The theta-gamma neural code. Neuron 77, 1002-1016. doi: 10.1016/j.neuron.2013.03.007

Lisman, J., and Redish, A. D. (2009). Prediction, sequences and the hippocampus. Philos. Trans. R. Soc. Lond. B Biol. Sci. 364, 1193-1201. doi: 10.1098/rstb.20 08.0316

Llorens-Martin, M., Blazquez-Llorca, L., Benavides-Piccione, R., Rabano, A., Hernandez, F., Avila, J., et al. (2014). Selective alterations of neurons and circuits related to early memory loss in Alzheimer's disease. Front. Neuroanat. 8:38. doi: 10.3389/fnana.2014.00038

López-Madrona, V. J., Perez-Montoyo, E., Alvarez-Salvado, E., Moratal, D., Herreras, O., Pereda, E., et al. (2020). Different theta frameworks coexist in the rat hippocampus and are coordinated during memory-guided and novelty tasks. eLife 9:e57313. doi: 10.7554/eLife.57313

Lu, L., Ren, Y., Yu, T., Liu, Z., Wang, S., Tan, L., et al. (2020). Control of locomotor speed, arousal and hippocampal theta rhythms by the nucleus incertus. Nat. Commun. 11:262. doi: 10.1038/s41467-019-14116-y

Macadar, O., Roig, J. A., Monti, J. M., and Budelli, R. (1970). The functional relationship between septal and hippocampal unit activity and hippocampal theta rhythm. Physiol. Behav. 5, 1443-1449. doi: 10.1016/0031-9384(70) 90134-4

MacDonald, C. J., Lepage, K. Q., Eden, U. T., and Eichenbaum, H. (2011). Hippocampal "time cells" bridge the gap in memory for discontiguous events. Neuron 71, 737-749. doi: 10.1016/j.neuron.2011.07.012

MacVicar, B. A., and Tse, F. W. (1989). Local neuronal circuitry underlying cholinergic rhythmical slow activity in CA3 area of rat hippocampal slices. J. Physiol. 417, 197-212. doi: 10.1113/jphysiol.1989.sp017797

Mamad, O., McNamara, H. M., Reilly, R. B., and Tsanov, M. (2015). Medial septum regulates the hippocampal spatial representation. Front. Behav. Neurosci. 9:166. doi: 10.3389/fnbeh.2015.00166

Markram, H., Lübke, J., Frotscher, M., and Sakmann, B. (1997). Regulation of synaptic efficacy by coincidence of postsynaptic APs and EPSPs. Science 275, 213-215. doi: 10.1126/science.275.5297.213

McCartney, H., Johnson, A. D., Weil, Z. M., and Givens, B. (2004). Theta reset produces optimal conditions for long-term potentiation. Hippocampus 14, 684-687. doi: 10.1002/hipo.20019

McClellan, A. D., and Jang, W. (1993). Mechanosensory inputs to the central pattern generators for locomotion in the lamprey spinal cord: resetting, entrainment and computer modeling. J. Neurophysiol. 70, 2442-2454. doi: 10.1152/jn.1993.70.6.2442

McCormick, D. A., and Prince, D. A. (1986). Mechanisms of action of acetylcholine in the guinea-pig cerebral cortex in vitro. J. Physiol. 375, 169-194. doi: 10.1113/jphysiol.1986.sp016112

McLennan, H., and Miller, J. J. (1974). The hippocampal control of neuronal discharges in the septum of the rat. J. Physiol. 237, 607-624. doi: 10.1113/jphysiol.1974.sp010500

McQuiston, A. R. (2010). Cholinergic modulation of excitatory synaptic input integration in hippocampal CA1. J. Physiol. 588, 3727-3742. doi: 10.1113/jphysiol.2010.188581

Mitchell, S. J., Rawlins, J. N., Steward, O., and Olton, D. S. (1982). Medial septal area lesions disrupt theta rhythm and cholinergic staining in medial entorhinal cortex and produce impaired radial arm maze behavior in rats. J. Neurosci. 2, 292-302. doi: 10.1523/JNEUROSCI.02-03-00292.1982

Moita, M. A., Rosis, S., Zhou, Y., LeDoux, J. E., and Blair, H. T. (2003). Hippocampal place cells acquire location-specific responses to the conditioned stimulus during auditory fear conditioning. Neuron 37, 485-497. doi: 10.1016/s0896-6273(03)00033-3

Monmaur, P., and Thomson, M. A. (1983). Topographic organization of septal cells innervating the dorsal hippocampal formation of the rat: special reference to both the CA1 and dentate theta generators. Exp. Neurol. 82, 366-378. doi: 10.1016/0014-4886(83)90409-0 
Montgomery, S. M., and Buzsáki, G. (2007). Gamma oscillations dynamically couple hippocampal CA3 and CA1 regions during memory task performance. Proc. Natl. Acad. Sci. U S A 104, 14495-14500. doi: 10.1073/pnas.0701 826104

Mormann, F., Fell, J., Axmacher, N., Weber, B., Lehnertz, K., Elger, C. E., et al. (2005). Phase/amplitude reset and theta-gamma interaction in the human medial temporal lobe during a continuous word recognition memory task. Hippocampus 15, 890-900. doi: 10.1002/hipo.20117

Müller, C., and Remy, S. (2018). Septo-hippocampal interaction. Cell Tissue Res. 373, 565-575. doi: 10.1007/s00441-017-2745-2

Musaeus, C. S., Nielsen, M. S., Musaeus, J. S., and Hogh, P. (2020). Electroencephalographic cross-frequency coupling as a sign of disease progression in patients with mild cognitive impairment: a pilot study. Front. Neurosci. 14:790. doi: 10.3389/fnins.2020.00790

Nuñez, A., and Buño, W. (1992). Intracellular effects of QX-314 and Cs+ in hippocampal pyramidal neurons in vivo. Exp. Neurol. 115, 266-270. doi: 10.1016/0014-4886(92)90061-t

Nuñez, A., Cervera-Ferri, A., Olucha-Bordonau, F., Ruiz-Torner, A., and Teruel, V. (2006). Nucleus incertus contribution to hippocampal theta rhythm generation. Eur. J. Neurosci. 23, 2731-2738. doi: 10.1111/j.1460-9568.2006. 04797.x

Nuñez, A., de Andres, I., and Garcia-Austt, E. (1991). Relationships of nucleus reticularis pontis oralis neuronal discharge with sensory and carbachol evoked hippocampal theta rhythm. Exp. Brain Res 87, 303-308. doi: 10.1007/BF00231847

Núñez, A., García-Austt, E., and Buño, W., Jr. (1987). Intracellular theta-rhythm generation in identified hippocampal pyramids. Brain Res. 416, 289-300. doi: 10.1016/0006-8993(87)90909-7

Núñez, A., Garcia-Austt, E., and Buño, W. (1990a). Slow intrinsic spikes recorded in vivo in rat CA1-CA3 hippocampal pyramidal neurons. Exp. Neurol. 109, 294-299. doi: 10.1016/S0014-4886(05)80020-2

Núñez, A., García-Austt, E., and Buño, W. (1990b). Synaptic contributions to theta rhythm genesis in rat CA1-CA3 hippocampal pyramidal neurons in vivo. Brain Res. 533, 176-179. doi: 10.1016/0006-8993(90)91814-w

O'Keefe, J., and Dostrovsky, J. (1971). The hippocampus as a spatial map. Preliminary evidence from unit activity in the freely-moving rat. Brain Res. 34, 171-175. doi: 10.1016/0006-8993(71)90358-1

O’Keefe, J., and Recce, M. L. (1993). Phase relationship between hippocampal place units and the EEG theta rhythm. Hippocampus 3, 317-330. doi: 10.1002/hipo. 450030307

Ovsepian, S. V., Anwyl, R., and Rowan, M. J. (2004). Endogenous acetylcholine lowers the threshold for long-term potentiation induction in the CA1 area through muscarinic receptor activation: in vivo study. Eur. J. Neurosci. 20, 1267-1275. doi: 10.1111/j.1460-9568.2004.03582.x

Pedemonte, M., Barrenechea, C., Nunez, A., Gambini, J. P., and GarciaAustt, E. (1998). Membrane and circuit properties of lateral septum neurons: relationships with hippocampal rhythms. Brain Res. 800, 145-153. doi: 10.1016/s0006-8993(98)00517-4

Penttonen, M., Kamondi, A., Acsady, L., and Buzsaki, G. (1998). Gamma frequency oscillation in the hippocampus of the rat: intracellular analysis in vivo. Eur. J. Neurosci. 10, 718-728. doi: 10.1046/j.1460-9568.1998. 00096.x

Petsche, H., Gogolák, G., and Stumpf, C. (1968). Septal unit firing and the shape of theta waves in the rabbit's hippocampus. Electroencephalogr. Clin. Neurophysiol. 24:390.

Petsche, H., Stumpf, C. H., and Gogolak, G. (1962). The significance of the rabbit's septum as a relay station between the midbrain and the hippocampus. I. The control of hippocampus arousal activity by the septum cells. Electroenceph. clin. Neurophysiol. 14, 202-211. doi: 10.1016/0013-4694(62)90030-5

Pfeiffer, B. E., and Foster, D. J. (2013). Hippocampal place-cell sequences depict future paths to remembered goals. Nature 497, 74-79. doi: 10.1038/nature12112

Pooler, A. M., Noble, W., and Hanger, D. P. (2014). A role for tau at the synapse in Alzheimer's disease pathogenesis. Neuropharmacology 76, 1-8. doi: 10.1016/j. neuropharm.2013.09.018

Posuszny, A. (2014). The contribution of electrical synapses to field potential oscillations in the hippocampal formation. Front. Neural Circuits 8:32. doi: 10.3389/fncir.2014.00032
Puma, C., Monmaur, V., Sharif, A., and Monmaur, P. (1996). Intraseptal infusion of selective and competitive glutamate receptor agonist NMDA and antagonist D-2-amino-5-phosphonopentanoic acid spectral implications for the physostigmine-induced hippocampal theta rhythm in urethaneanesthetized rats. Exp. Brain Res. 109, 384-392. doi: 10.1007/BF00229622

Radulovacki, M., and Adey, W. R. (1965). The hippocampus and the orienting reflex. Exp. Neurol. 12, 68-83. doi: 10.1016/0014-4886(65)90099-3

Ridler, T., Witton, J., Phillips, K. G., Randall, A. D., and Brown, J. T. (2020). Impaired speed encoding and grid cell periodicity in a mouse model of tauopathy. Elife 9:e59045. doi: 10.7554/eLife.59045

Rivas, J., Gaztelu, J. M., and Garcia-Austt, E. (1996). Changes in hippocampal cell discharge patterns and theta rhythm spectral properties as a function of walking velocity in the guinea pig. Exp. Brain Res. 108, 113-118. doi: 10.1007/BF00242908

Robinson, J., Manseau, F., Ducharme, G., Amilhon, B., Vigneault, E., El Mestikawy, S., et al. (2016). Optogenetic activation of septal glutamatergic neurons drive hippocampal theta rhythms. J. Neurosci. 36, 3016-3023. doi: 10.1523/JNEUROSCI.2141-15.2016

Roig, J. A., Budelli, R., Macadar, O., and Monti, J. M. (1970). Hippocampal theta rhythm in relation with unit discharges in septum and hippocampus. Electroencephalogr. Clin. Neurophysiol. 28:520.

Rubio, A., Perez, M., de Lecea, L., and Avila, J. (2008). Effect of cortistatin on tau phosphorylation at Ser262 site. J. Neurosci. Res. 86, 2462-2475. doi: 10.1002/jnr. 21689

Sakmann, B. (2017). From single cells and single columns to cortical networks: dendritic excitability, coincidence detection and synaptic transmission in brain slices and brains. Exp. Physiol. 102, 489-521. doi: 10.1113/EP085776

Sayer, R. J., Redman, S. J., and Andersen, P. (1989). Amplitude fluctuations in small EPSPs recorded from CA1 pyramidal cells in the guinea pig hippocampal slice. J. Neurosci. 9, 840-850. doi: 10.1523/JNEUROSCI.09-03-00 840.1989

Schiller, J., and Schiller, Y. (2001). NMDA receptor-mediated dendritic spikes and coincident signal amplification. Curr. Opin. Neurobiol. 11, 343-348. doi: 10.1016/s0959-4388(00)00217-8

Schoenfeld, T. J., Kloth, A. D., Hsueh, B., Runkle, M. B., Kane, G. A., Wang, S. S., et al. (2014). Gap junctions in the ventral hippocampal-medial prefrontal pathway are involved in anxiety regulation. J. Neurosci. 34, 15679-15688. doi: 10.1523/JNEUROSCI.3234-13.2014

Schomburg, E. W., Fernandez-Ruiz, A., Mizuseki, K., Berenyi, A., Anastassiou, C. A., Koch, C., et al. (2014). Theta phase segregation of input-specific gamma patterns in entorhinal-hippocampal networks. Neuron 84, 470-485. doi: 10.1016/j.neuron.2014.08.051

Schwartzkroin, P. A. (1975). Characteristics of CA1 neurons recorded intracellularly in the hippocampal in vitro slice preparation. Brain Res. 85, 423-436. doi: 10.1016/0006-8993(75)90817-3

Sederberg, P. B., Schulze-Bonhage, A., Madsen, J. R., Bromfield, E. B., McCarthy, D. C., Brandt, A., et al. (2007). Hippocampal and neocortical gamma oscillations predict memory formation in humans. Cereb. Cortex 17 , 1190-1196. doi: 10.1093/cercor/bhl030

Semba, K., and Komisaruk, B. R. (1978). Phase of the theta wave in relation to different limb movements in awake rats. Electroencephalogr. Clin. Neurophysiol. 44, 61-71. doi: 10.1016/0013-4694(78)90105-0

Singer, W. (1998). Consciousness and the structure of neuronal representations. Philos. Trans. R. Soc. Lond. B Biol. Sci. 353, 1829-1840. doi: 10.1098/rstb.19 98.0335

Sirota, A., Montgomery, S., Fujisawa, S., Isomura, Y., Zugaro, M., and Buzsaki, G. (2008). Entrainment of neocortical neurons and gamma oscillations by the hippocampal theta rhythm. Neuron 60, 683-697. doi: 10.1016/j.neuron.2008. 09.014

Smythe, J. W., Colom, L. V., and Bland, B. H. (1992). The extrinsic modulation of hippocampal theta depends on the coactivation of cholinergic and GABA-ergic medial septal inputs. Neurosci. Biobehav. Rev. 16, 289-308. doi: 10.1016/s01497634(05)80203-9

Stewart, M., and Fox, S. E. (1989). Firing relations of medial septal neurons to the hippocampal theta rhythm in urethane anesthetized rats. Exp. Brain Res. 77, 507-516. doi: 10.1007/BF00249604

Stumpf, C., Petsche, H., and Gogolak, G. (1962). The significance of the rabbit's septum as a relay station between the midbrain and the hippocampus. II. 
The differential influence of drugs upon the septal cell firing pattern and the hippocampus theta activity. Electroencephalogr. Clin. Neurophysiol. 14, 212-219. doi: 10.1016/0013-4694(62)90031-7

Sugar, J., and Moser, M. B. (2019). Episodic memory: neuronal codes for what, where and when. Hippocampus 29, 1190-1205. doi: 10.1002/hipo.23132

Takahashi, M., Nishida, H., Redish, A. D., and Lauwereyns, J. (2014). Theta phase shift in spike timing and modulation of gamma oscillation: a dynamic code for spatial alternation during fixation in rat hippocampal area CA1. J. Neurophysiol. 111, 1601-1614. doi: 10.1152/jn.00395.2013

Tort, A. B., Kramer, M. A., Thorn, C., Gibson, D. J., Kubota, Y., Graybiel, A. M., et al. (2008). Dynamic cross-frequency couplings of local field potential oscillations in rat striatum and hippocampus during performance of a T-maze task. Proc. Natl. Acad. Sci. U S A 105, 20517-20522. doi: 10.1073/pnas. 0810524105

Tóth, K., Freund, T. F., and Miles, R. (1997). Disinhibition of rat hippocampal pyramidal cells by GABAergic afferents from the septum. J. Physiol. 500, 463-474. doi: 10.1113/jphysiol.1997.sp022033

Traub, R. D., Bibbig, A., LeBeau, F. E., Buhl, E. H., and Whittington, M. A. (2004). Cellular mechanisms of neuronal population oscillations in the hippocampus in vitro. Annu. Rev. Neurosci. 27, 247-278. doi: 10.1146/annurev.neuro.27. 070203.144303

Unal, C. T., Golowasch, J. P., and Zaborszky, L. (2012). Adult mouse basal forebrain harbors two distinct cholinergic populations defined by their electrophysiology. Front. Behav. Neurosci. 6:21. doi: 10.3389/fnbeh.2012. 00021

Unal, G., Crump, M. G., Viney, T. J., Eltes, T., Katona, L., Klausberger, T., et al. (2018). Spatio-temporal specialization of GABAergic septo-hippocampal neurons for rhythmic network activity. Brain Struct. Funct. 223, 2409-2432. doi: 10.1007/s00429-018-1626-0

Vandecasteele, M., Varga, V., Berenyi, A., Papp, E., Bartho, P., Venance, L., et al. (2014). Optogenetic activation of septal cholinergic neurons suppresses sharp wave ripples and enhances theta oscillations in the hippocampus. Proc. Natl. Acad. Sci. U S A 111, 13535-13540. doi: 10.1073/pnas.1411233111

Vanderwolf, C. H., Kramis, R., and Robinson, T. E. (1977). Hippocampal electrical activity during waking behavior and sleep: analyses using centrally acting drugs. Ciba Found. Symp. 58, 199-226. doi: 10.1002/9780470720394.ch10

Varga, V., Hangya, B., Kranitz, K., Ludanyi, A., Zemankovics, R., Katona, I., et al. (2008). The presence of pacemaker HCN channels identifies theta rhythmic GABAergic neurons in the medial septum. J. Physiol. 586, 3893-3915. doi: $10.1113 /$ jphysiol.2008.155242

Vertes, R. P. (2005). Hippocampal theta rhythm: a tag for short-term memory. Hippocampus 15, 923-935. doi: 10.1002/hipo.20118

Vinogradova, O. S. (1995). Expression, control and probable functional significance of the neuronal theta-rhythm. Prog. Neurobiol. 45, 523-583. doi: 10.1016/0301-0082(94)00051-i

Ward, H. P. (1960). Basal tegmental self-stimulation after septal ablation in rats. Arch. Neurol. 3, 158-162. doi: 10.1001/archneur.1960.00450020038006
Whishaw, I. Q., and Vanderwolf, C. H. (1973). Hippocampal EEG and behavior: changes in amplitude and frequency of RSA (theta rhythm) associated with spontaneous and learned movement patterns in rats and cats. Behav. Biol. 8, 461-484. doi: 10.1016/s0091-6773(73)80041-0

Wikenheiser, A. M., and Redish, A. D. (2015). Hippocampal theta sequences reflect current goals. Nat. Neurosci. 18, 289-294. doi: 10.1038/nn.3909

Wilson, M. A., and McNaughton, B. L. (1993). Dynamics of the hippocampal ensemble code for space. Science 261, 1055-1058. doi: 10.1126/science.8351520

Winfree, A. T. (1977). Phase control of neural pacemakers. Science 197, 761-763. doi: $10.1126 /$ science. 887919

Wood, E. R., Dudchenko, P. A., and Eichenbaum, H. (1999). The global record of memory in hippocampal neuronal activity. Nature 397, 613-616. doi: $10.1038 / 17605$

Wyble, B. P., Linster, C., and Hasselmo, M. E. (2000). Size of CA1-evoked synaptic potentials is related to theta rhythm phase in rat hippocampus. J. Neurophysiol. 83, 2138-2144. doi: 10.1152/jn.2000.83.4.2138

Yakel, J. L. (2012). Nicotinic ACh receptors in the hippocampus: role in excitability and plasticity. Nicotine Tob. Res. 14, 1249-1257. doi: 10.1093/ntr/nts091

Yamasaki, M., Matsui, M., and Watanabe, M. (2010). Preferential localization of muscarinic M1 receptor on dendritic shaft and spine of cortical pyramidal cells and its anatomical evidence for volume transmission. J. Neurosci. 30, 4408-4418. doi: 10.1523/JNEUROSCI.5719-09.2010

Zhang, K., Ginzburg, I., McNaughton, B. L., and Sejnowski, T. J. (1998). Interpreting neuronal population activity by reconstruction: unified framework with application to hippocampal place cells. J. Neurophysiol. 79, 1017-1044. doi: 10.1152/jn.1998.79.2.1017

Zhang, X., Zhong, W., Brankack, J., Weyer, S. W., Muller, U. C., Tort, A. B., et al. (2016). Impaired theta-gamma coupling in APP-deficient mice. Sci. Rep. 6:21948. doi: 10.1038/srep21948

Zola, S. M., and Squire, L. R. (2001). Relationship between magnitude of damage to the hippocampus and impaired recognition memory in monkeys. Hippocampus 11, 92-98. doi: 10.1002/hipo.1027

Zutshi, I., Brandon, M. P., Fu, M. L., Donegan, M. L., Leutgeb, J. K., and Leutgeb, S. (2018). Hippocampal neural circuits respond to optogenetic pacing of theta frequencies by generating accelerated oscillation frequencies. Curr. Biol. 28, 1179.e3-1188.e3. doi: 10.1016/j.cub.2018.02.061

Conflict of Interest: The authors declare that the research was conducted in the absence of any commercial or financial relationships that could be construed as a potential conflict of interest.

Copyright (c) 2021 Nuñez and Buño. This is an open-access article distributed under the terms of the Creative Commons Attribution License (CC BY). The use, distribution or reproduction in other forums is permitted, provided the original author(s) and the copyright owner(s) are credited and that the original publication in this journal is cited, in accordance with accepted academic practice. No use, distribution or reproduction is permitted which does not comply with these terms. 